\title{
Acoustic monitoring of gas emissions from the seafloor. Part I: quantifying the volumetric flow of bubbles
}

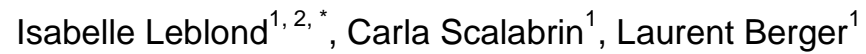

\author{
${ }^{1}$ IFREMER, BP 70, 29280, Plouzané, France \\ ${ }^{2}$ ENSTA Bretagne, 2 rue François Verny, 29806, Brest Cedex 9, France \\ *: Corresponding author : Isabelle Leblond, email address : isabelle.leblond@ensta-bretagne.fr
}

\begin{abstract}
:
Three decades of continuous ocean exploration have led us to identify subsurface fluid related processes as a key phenomenon in marine earth science research. The number of seep areas located on the seafloor has been constantly increasing with the use of multi-scale imagery techniques. Due to recent advances in transducer technology and computer processing, multibeam echosounders are now commonly used to detect submarine gas seeps escaping from the seafloor into the water column. A growing number of en-route surveys shows that sites of gas emissions escaping from the seafloor are much more numerous than previously thought. Estimating the temporal variability of the gas flow rate and volumes escaping from the seafloor has thus become a challenge of relevant interest which could be addressed by sea-floor continuous acoustic monitoring. Here, we investigate the feasibility of estimating the volumetric flow rates of gas emissions from horizontal backscattered acoustic signals. Different models based on the acoustic backscattering theory of bubbles are presented. The forward volume backscattering strength and the inversion volumetric flow rate solutions were validated with acoustic measurements from artificial gas flow rates generated in controlled sea-water tank experiments. A sensitivity analysis was carried out to investigate the behavior of the $120-\mathrm{kHz}$ forward solution with respect to model input parameters (horizontal distance between transducer and bubble stream, bubble size distribution and ascent rate). The most sensitive parameter was found to be the distance of the bubble stream which can affect the volume backscattering strength by $20 \mathrm{~dB}$ within the horizontal range of $0-200 \mathrm{~m}$. Results were used to derive the detection probability of a bubble stream for a given volume backscattering strength threshold according to different bubble flow rates and horizontal distance.
\end{abstract}

Keywords: Seafloor observatory ; Water column acoustics ; Forward and inverse modeling ; Fisheries echosounders ; Acoustic backscattering ; Gas emissions ; Bubbles ; Water tank experiments 


\section{Introduction}

Until very recently, acoustic methods in marine geosciences have been mostly used to explore the seabed and to image sub-bottom units, with little attention to the water column, despite the extensive use in fisheries studies. However, recent advances in technology and computer processing now allow carrying out 3D acoustic surveys of the entire water column, revealing that gassy sediments and free gas emissions from the seafloor are much more frequent than expected (e.g. Fleischer et al. 2001; Judd and Hovland 2007). The gases emitted from cold seeps in the marine environment are principally composed of methane, raising major questions, e.g.: on whether or not the methane released from the seafloor reaches the atmosphere; on the dynamic variability of gas hydrates dissociation (e.g., Paull et al. 1995; Westbrook et al. 2009), on the relation between gas emissions and seismicity (Judd 2004; Géli et al.2008, Hsu et al. 2013).

En-route surveys allow the detection of gas emissions using ship-board or deep-towed active acoustic devices (Sauter et al., 2006; McGinnis et al. 2006; Nikolovska et al. 2008; Foucher et al., 2010) and can also provide information about temporal variation of gas emission activity at short time or year-based scales. Hsu et al. (2013) observed the temporal variability of one gas emission source with a $38 \mathrm{kHz}$ hull-mounted single-beam sounder at a 24-hour scale and Dupré et al. (2014) report results of long-lasting gas emissions observed with hullmounted single-beam and multibeam (ME-70) sounders during routine fisheries surveys carried out every year. However, continuous observation of the temporal variability of gas bubble flow rates requires a specific monitoring approach using underwater observatories (e.g. Rona et al. 1991; Greinert et al. 2006; Greinert 2008; Ruhl et al. 2011).

Since the early work of Rona et al (1991), focusing on in-situ acoustic imaging of hydrothermal plumes from the East Pacific Rise, several studies have been carried out referring to the use of active acoustic methods for detecting bubbles in the water column. In (Greinert et al. 2006), rising speed values of bubbles are estimated from echograms of gas emissions. In Artemov et al. (2007), values of rising speed and bubble diameters are estimated with a split-beam sounder. Experimental and methodological studies have been performed in water tanks or ship docks for calibrating the acoustic response of gas bubble releases in controlled environments (Greinert and Nutzel 2004; Ostrovsky et al. 2008). Greinert and Nutzel (2004) provide an empirical relationship between volume backscattering strength and bubble flows based on experimental data recorded with a calibrated echosounder illuminating horizontally an artificial bubble release generated in a ship dock. Empirical relationships were also established between gas volumes and backscattering cross-section of individual bubbles in experimental conditions, and the volume backscattering coefficient was shown to be a good proxy of the total volume of bubbles per cubic meter of water (Ostrovsky et al. 2008). Nikolovska et al. (2008) used data collected on natural gas seeps in the Black Sea with a horizontal-looking sonar mounted on a remotely operated vehicle (ROV) to obtain an empirical correlation between the gas flux and the backscattering intensity to quantify the flux of bubbles.

In most of these studies, a direct relationship is assumed between backscattering strength and the amount of bubbles in the water column, therefore flow estimates are usually derived from empirical relationships or by inverse modeling from the acquired real data. Despite the importance of these earlier results, it would be useful to broaden the conceptual framework and to investigate the relevance of different models that could be used to predict the backscattering of bubbles and seepage flow rates. 
The first objective of this study is to extend the methodology and validate forward and inverse modeling approaches. In the forward modeling approach, several deterministic equations based on physical and acoustical properties of bubble flows are used to compute the theoretical backscattering value. The different theoretical results were then compared with data from tank experiments in order to select which forward model can be taken to provide the most reasonable accurate relationship between volumetric bubble flows and backscatter measurements. In the inverse modeling approach, the acquired real acoustic data from tank experiments were used to estimate the volumetric bubble flow parameter of the physical models. The estimated volumetric bubble flow values were then compared to the artificial bubble flows generated in the tank.

The second objective of the study is to present the most relevant results derived from a sensitivity analysis of the forward model approach.

\section{Review of bubble backscatter theory and forward/inverse modeling}

The intensity backscattered by one single bubble is often modeled as an equivalent surface named acoustic backscattering cross-section, hereafter noted $\sigma_{b s}$, in $\mathrm{m}^{2}$ (e.g., Medwin et al. 1998; Lurton 2002; Simmonds et al. 2005).

It is assumed that for several bubbles, the total backscattering value, named volume backscattering coefficient $\left(\mathrm{s}_{\mathrm{v}}\right.$ in $\left.\mathrm{m}^{-1}\right)$, is the contribution of all single targets:

$$
s_{v}=\int \sigma_{b s} n(a) d a
$$

where $n(a)$ is the concentration of bubbles, per classes of radii

$$
n(a) d a=\frac{\text { number of bubbles of radius between } a \text { and } a+d a}{\text { volume }}
$$

According to (1), the volume backscattering coefficient is mainly controlled by two parameters: the distribution of bubbles sizes and the acoustic model describing the single bubble backscattering cross-section.

The backscattering cross-section and the volume backscattering coefficient are often expressed in decibels. Thereafter, the backscattering cross-section of a single bubble will be expressed as the target strength:

$$
\mathrm{TS}=10 \log _{10}\left(\sigma_{\mathrm{bs}}\right)\left(\mathrm{dB} \text { re } 1 \mathrm{~m}^{2}\right)
$$

The volume backscattering coefficient of multiple discrete bubbles will be expressed as the volume backscattering strength: 


$$
S_{v}=10 \log _{10}\left(S_{v}\right)\left(d B \text { re } 1 m^{-1}\right)
$$

The different models used to compute the acoustic backscattering cross-section of a single bubble and the distribution of bubbles sizes are given in the next two sections.

\subsection{Acoustic backscattering cross-section of a single gas bubble}

Underwater acoustic literature presents several acoustic models to predict the bubble acoustic backscattering cross-section according to different parameters as bubble size, bubble morphology, acoustic frequency or the environment characteristics. Most of them were developed for spherical bubbles (Medwin et al. 1998; Stanton 1989), but some models can work with additional target shapes such as prolate spheroids or cylinders and various classes of materials (fluid, elastic, rigid and gaseous) (Stanton 1989).

In this study, bubble acoustic backscattering cross-sections were predicted using three acoustic models, one from Medwin and two from Stanton for gas-filled spheres and gas-filled prolate spheroids. These models were adapted to three different morphology frameworks to account for more „natural" bubble shapes.

The Medwin formula is derived from the mechanical equation of a mass-stiffness system with damping constants (Medwin et al. 1998). The final expression is given by:

$$
\sigma_{b s} \approx \frac{a^{2}}{\left[\left(f_{0} / f\right)^{2}-1\right]^{2}+(k a)^{2}}
$$

where $a$ is the bubble radius $(m), k$ is the acoustic wave number of the surrounding fluid medium $\left(\mathrm{m}^{-1}\right), f$ is the frequency of the active source $(\mathrm{Hz})$ and $\mathrm{f}_{0}$ is the resonance frequency $(\mathrm{Hz})$ of the bubble which relates to $\mathrm{z}$, the depth of the bubble $(\mathrm{m})$ as:

$$
f_{0} \approx \frac{3.15}{a} \sqrt{1+0.1 \mathrm{z}} \quad \text { for methane }
$$

The Medwin formula is a first-order approximation of the backscattering cross section of an ideal gas sphere, i.e. for small ka (Johnson 1977). For a fluid sphere, Anderson (1950) gives the general solution of the three dimensional wave equation in terms of spherical harmonics. From this solution, Johnson derived an expression named "high-pass model" which is a firstorder approximation of the backscattering cross section for small ka and an asymptotic value for large ka (Johnson 1977). Stanton (1989) refines and generalizes the Johnson"s approach, and describes the backscattering by other bodies and shapes and gas as fluid. 
The high-pass solution of Stanton's model for the backscattering cross-section of a gas-filled sphere of radius $a$ is given by:

$$
\sigma_{b s} \approx \frac{a^{2}(k a)^{4} \alpha_{\pi s}^{2} G}{1+\frac{4(k a)^{4} \alpha_{\pi s}^{2}}{R_{g}{ }^{2} F}}
$$

where:

$\alpha_{\pi s} \approx \frac{1-d_{r} s_{r}{ }^{2}}{3 d_{r} s_{r}{ }^{2}}+\frac{1-\mathrm{s}_{\mathrm{r}}}{1+2 \mathrm{~s}_{\mathrm{r}}}$

is a factor taking into account the density ratio $d_{r}=\rho_{\text {gas }} / \rho_{\text {water }}$ (density of the body material/density of the surrounding fluid) and the sound speed ratio $\mathrm{S}_{\mathrm{r}}=\mathrm{c}_{\text {gas }} / \mathrm{c}_{\text {water }}$;

$G=1+85 e^{\left[-5.10^{5}(k a-0.0135)^{2}\right]}$

is an heuristic function to produce nulls and/or peaks in the curve;

$R_{g}=\frac{d_{r} s_{r}-1}{d_{r} s_{r}+1}$

is the Rayleigh reflection coefficient used to scale the amplitude echo given by the planewave-plane interface as a first approximation to account for the penetrability of the object;

$F=1+0.5(k a)^{-0.75}$

is an heuristic function to account for deviations in $\sigma_{b s}$ when the geometry is irregular.

The high-pass solution for the backscattering cross-section of a gas-filled prolate spheroid, of major-axis total length $L$ and semi-minor axis $a$ is given by:

$$
\sigma_{b s} \approx \frac{\frac{1}{9} L^{2}(k a)^{4} \alpha_{\pi s}^{2} G}{\left[1+\frac{\frac{16}{9}(k a)^{4} \alpha_{\pi s}^{2}}{R_{g}{ }^{2} F}\right]}
$$

with: 
$\alpha_{\pi \mathrm{s}} \approx \frac{1-d_{r} s_{r}{ }^{2}}{2 d_{r} s_{r}{ }^{2}}+\frac{1-\mathrm{d}_{\mathrm{r}}}{1+\mathrm{d}_{\mathrm{r}}}, G=1+6 e^{\left[-7.10^{5}(k a-0.0045)^{2}\right]} \quad$ and $\mathrm{F}=1$.

Figure 1 shows the backscattering cross-section values, expressed as target strength, computed by the above formulae for gas-filled spheres $(\mathrm{g}=0.012, \mathrm{~h}=0.2277, \mathrm{z}=0 \mathrm{~m})$ of radius between $5.0 \times 10^{-4}$ and $10 \mathrm{~mm}$ using a fixed frequency of $120 \mathrm{kHz}$. The shape of the resulting curves are quite similar, however, TS values estimated by the Stanton models are lower than those estimated by the Medwin formula with an inversion of this trend for radius $\geq$ $0.4 \mathrm{~mm}$ in the geometric scattering regime. The resonance peak of the prolate spheroid model is not well defined (see Stanton 1989).

These three formulae have been developed for gas-filled spheres or prolate spheroids; however, based on video data collected in a water tank (Fig. 2a), bubbles in the water column are neither spheres, nor prolate spheroids, but rather oblate spheroids (Fig. $2 \mathrm{~b}$ ). The oblate shape of bubbles released in seepage areas has also been observed in several studies (Leifer et al. 2003; Sauter et al. 2006; Ostrovsky et al. 2008; Schneider von Deimling et al. 2011). Different adaptations have thus been suggested, in order to take into account the oblate shape of the bubbles. One of them consists in the full modeling of the backscattering response of an oblate spheroid. The Kirchhoff-ray mode approximation (KRM) (e.g. Clay et al. 1994) allows the computation of the acoustic backscattering cross-section for high frequencies, whatever the shape of the target. Unfortunately, KRM approximations do not apply for the case of bubble backscattering model due to the small size of the targets (by definition, the validity of KRM model is for $\lambda<<L$ with $\lambda$ the wavelength and $L$ the typical size of the body).

The approach investigated here consists in using the Medwin and Stanton models for gas filled objects and test them for three different computation methods and account for the bubble oblate morphology.

The first method just considers a sphere with a radius corresponding to the semi-major axis of an oblate spheroid. The second method considers a sphere with a radius corresponding to the semi-minor axis of the oblate spheroid and applies a multiplicative factor on the volume backscattering strength, according to the flatness of the bubble, or its orientation to the echosounder. Tang (1996) provides the backscattering coefficient of an oblate spheroid as a function of flatness for a frequency of $40 \mathrm{kHz}$. From polar curves of backscattering amplitudes as a function of flatness and tilt values, the multiplicative factor can be estimated and applied for other frequencies or bubble radii.

The third method uses the concept of an equivalent sphere which is a sphere with the same volume of the required oblate spheroid. For an oblate spheroid with semi-major axis $a$ and semi-minor axis $b$, the radius of the equivalent sphere is computed as: $r_{e q}=\left(a^{2} b\right)^{1 / 3}$.

For each model, Medwin for spheres, Stanton for spheres and Stanton for prolate spheroids, different gaseous spheres were tested: i) radius equal to the semi-major axis of the required oblate spheroid; ii) radius equal to the semi-minor axis of the required oblate spheroid with a 
multiplicative factor applied on volume backscattering strength values; and iii) equivalent sphere. Examples of TS estimates for different theoretical oblate bubble sizes are illustrated in Table 1. In these examples, the flatness of the bubble is constant and equal to 2. Scaled figures of the theoretical oblate bubble, with semi-major axis of $2 \mathrm{~mm}$ and semi-minor axis of $1 \mathrm{~mm}$, and the corresponding spheres are also shown in Table 1.

\subsection{Forward modeling the bubble concentration via echo-integration}

The bubble volumetric flow $F_{v}$ is:

$$
F_{v}=\sum_{a_{0}}^{a_{N}} N_{t}(a) \frac{4}{3} \pi a^{3}
$$

where $N_{t}$ is the number of bubbles of radius $a\left(a_{0}<a<a_{N}\right)$ escaping from the seep per time unit.

Assuming a steady volumetric flow, at least during the time required for the bubbles to rise one meter, the number of bubbles per meter $\left(N_{m}\right)$ can be estimated from the number of bubbles per time unit and the ascent rate $\left(v_{\text {ascent }}\right)$ of the bubbles:

$$
N_{m}(a)=\frac{N_{t}(a)}{v_{\text {ascent }}}
$$

The number of insonified bubbles can be computed from the number of bubbles per meter weighted by the echo-integrated sampling volume, which depends on the selected geometry, either vertical or horizontal insonification (Fig. 3).

For a vertical insonification of a point bubble source and assuming that the acoustic beam intersects the entire horizontal spreading of the actual bubble plume along its vertical rising, the number of bubbles in the integrated volume $\left(N_{i}\right)$ will essentially depend on the integration bin width $\left(l_{i}\right)$ :

$$
N_{i}(a)=N_{m}(a) \times l_{i}
$$

For a horizontal insonification of a point bubble source, the thickness of the horizontal integration bin is less relevant provided that the entire horizontal spreading of the actual bubble plume is covered by the width of the integrated layer at the integration distance. In this case, the number of bubbles in the integrated volume $\left(N_{i}\right)$ will essentially be constrained by the beam width at the intersection distance with the rising bubbles. Considering that the horizontal spreading of the bubble plume is small compared to the beam width and the 
source is aligned with the axis of the beam, the number of bubbles depends on the beam diameter:

$$
N_{i}(a)=N_{m}(a) \times 2 R \quad(10 b)
$$

where $R$ is the beam radius.

For both geometries, vertical or horizontal insonification, the value of the echo-integrated sampling volume is:

$$
V_{i}=S_{i} \times l_{i}=\pi \times R^{2} \times l_{i}
$$

where $S_{i}$ is the insonified area at the intersect with the rising bubbles.

The bubble concentration in a given echo-integrated sampling volume is:

$$
n(a)=\frac{N_{i}}{V_{i}}
$$

Hence, for the vertical insonification geometry, the bubble concentration can be computed by:

$$
n(a)=\frac{N_{t} / v_{a s c e n t}}{\pi \times R^{2}}
$$

and in the horizontal insonification geometry, the bubble concentration can be expressed as:

$$
n(a)=2 \times \frac{N_{t} / v_{a s c e n t}}{\pi \times l_{i} \times R}
$$

The acoustic backscattering cross-section of a single bubble given by expressions (5), (6) or (7), the bubbles concentration given by expression (13a) or (13b) and equation (1) will be used to compute the theoretical volume backscattering coefficients of empirical volumetric bubble flows according to the forward modeling. 


\subsection{Estimating volumetric bubble flow by inverse modeling}

Considering a given volumetric flow $F_{v 1}$, the number of bubbles per time unit $N_{t 1}$ (a) can be computed according to equation (8) and the concentration of bubbles in the echo-integrated sampling volume $n_{1}(a)$ is derived following the steps from equation (9) to (13a) or (13b)).

The volume backscattering coefficient $s_{v 1}$ corresponding to this arbitrary volumetric flow can also be computed according to equation (1):

$$
s_{v 1}=\int \sigma_{b s} n_{1}(a) d a
$$

The ratio between the acoustic measured volume backscattering coefficient $\left(s_{v m e s}\right)$ and the theoretical value $s_{v 1}$ of the arbitrary volumetric flow computed above can be used as a simple solution for the inversion of the model:

$$
\alpha=\frac{s_{v m e s}}{s_{v 1}}
$$

Assuming a steady bubble size distribution, the actual concentration of bubbles in the insonified volume can be computed from the ratio $\alpha$ and the concentration of bubbles of the arbitrary flow $n_{1}$ :

$$
n_{m e s}=\alpha \times n_{1}(a)
$$

For vertical insonification, the number of bubbles per time unit is:

$$
N_{t}(a)=\frac{s_{v m e s}}{S_{v 1}} \times n_{1}(a) \times \pi \times R^{2} \times v_{\text {ascent }}
$$

For horizontal insonification, the number of bubbles per time unit is:

$$
N_{t}(a)=\frac{s_{v m e s}}{s_{v 1}} \times n_{1}(a) \times \pi \times R \times l_{i} \frac{v_{\text {ascent }}}{2}
$$


The number of bubbles per time unit computed from equations (17) or (18) can then be used to estimate the volumetric bubble flow according to equation (8).

\section{Validation of forward and inverse modeling}

\subsection{Experimental set up}

Two experiments were carried out at the seawater testing pool facilities of Ifremer (Brest), in September and December 2010, to collect acoustic and video data of artificially generated bubble releases. Measured data were used to verify the consistency of the experimental set up with natural bubble seeps and to provide inputs in the validation of the forward and inverse modeling approaches presented in this study.

The tank is $12.5 \mathrm{~m}$ wide and $50 \mathrm{~m}$ long, with water depths ranging between 10 to $20 \mathrm{~m}$. The experimental set up includes a bubble production system designed to simulate a gas release escaping from the seafloor, Simrad EK-60 split-beam echosounders calibrated according to the method described by Foote (1987) and two waterproof camcorders located a few meters away from the bubble release. Flow rates generated by the bubble production system were controlled with a flowmeter at the surface, but values indicated here are compensated for the depth of the bubble release. Different outlets (air stones and a plastic outlet of $1 \mathrm{~mm}$ in diameter) were also used to control the number of released bubbles per unit of time. According to availability of acoustic systems, vertical and horizontal insonification data could be simultaneously acquired with two $200 \mathrm{kHz}$ echosounders, while some experiments were carried out using only a horizontal looking $120 \mathrm{kHz}$ echosounder.

Bubble size, morphology and ascent rate are usually presented as sources of potential bias or measurement errors in forward or inverse modeling. Different experimental set ups provided results for varying bubble flow rates allowing to image releases of single bubbles time-spaced by more than 1 second, line streams of bubbles or clouds with varying bubble density.

The ascent rate of bubbles in the tank was estimated from cross-validation of acoustic and video data with overall experiment values ranging between 15 and $35 \mathrm{~cm} / \mathrm{s}$. Acoustic derived ascent rates were estimated using the approach developed in Greinert (2006). Several studies reported bubble ascent rates from in situ measurements within this interval (Greinert et al. 2006, Ostrovsky et al. 2008, Rehder et al. 2009). This is also in accordance to experimental observations summarized in Clift et al. (1978). The spread of values observed here is related to different experimental conditions (type of outlet, flow rates, bubble size and shape distributions) affecting the rising speed of bubbles in the tank. However, for every experiment, the dispersion of measured data around the mean value was low (e.g., mean value of $31.6 \pm 1.8 \mathrm{~cm} / \mathrm{s}$ for one measurement sequence).

The bubble size distributions and related bubble morphology were derived from video data. The output of the image analysis processing provides the best fitting ellipse to every single bubble and estimates the major $a$ and minor $b$ axis lengths. Overall bubble radius or semimajor axis experimental values were within the 1-10 $\mathrm{mm}$ range with a dominant 3-mm modal 
value. The bubble size distributions observed here are within the range values reported by several in situ or experimental bubble seep studies (Rehder et al. 2002; Greinert and Nutzel 2004; Sauter et al. 2006; McGinnis et al. 2006; Nikolovska et al. 2008; Ostrovsky et al. 2008; Rehder et al. 2009; Leifer 2010) and can be assumed to reasonably simulate a natural gas seep. Figure 4a shows the bubble size distribution of one experiment which can be well fit with a log-normal distribution. Bubble shape is represented by the flatness coefficient $a / b$ with 1 corresponding to a spherical bubble. Experimental results confirm the oblate shape of bubbles generated in the tank (Fig. 4b). Although data are quite noisy, the flatness appears to increase with the semi-major axis meaning that large bubbles are more flattened than small ones. The flatness value used in the model validation process is estimated through the logarithmic fit equation of data.

\subsection{Validating forward modeling by acoustic and video data}

The goal of the validation is to determine, among the various models tested here, which model fits best the data. In this experiment, video and acoustic records were synchronized. The bubble production system was located on the tank floor (10-m depth) generating a weak flow rate of less than $0.1 \mathrm{l} / \mathrm{min}$ and intermittent air bubble streams with periods of more than 30 seconds. The horizontal insonification geometry was used with a pulse rate of $1 \mathrm{~Hz}$ and the transducer was located $15 \mathrm{~m}$ away of the bubble release. The acoustic beam intercepts the bubble stream in the mid-path rising towards the surface ( $5 \mathrm{~m}$ off the bottom). Video data provided estimates of bubble size and shape and the number of bubbles per insonified stream ranging from few bubbles to tens of bubbles per image (Fig 5a). The input parameters used to estimate the theoretical volume backscattering coefficient by the forward modeling approach are listed in Table 2. The theoretical volume backscattering coefficients, $s_{v}$, were computed from equations (1) and (13b) where the $N_{t} / v_{a s c e n t}$ term was replaced by the total number of insonified bubbles per released stream from image analysis data. This computation subterfuge is only possible because bubble groups were very well discriminated in space-time domains. Theoretical results were then compared to the empirical acoustic data.

The acoustic response of the intermittent streams of bubbles generated for the experiment are visualized as aligned patches of echoes within a layer located at a fixed horizontal distance from the transducer (Fig. 5b). Maximum volume backscattering strength measurements were plotted as a function of time, where regular peaks correspond to the bubble streams crossing the horizontal acoustic beam (Fig. 6a). For each model, the computed volume backscattering strength values were compared to the peaks of volume backscattering strength measurements provided by acoustic data (Fig. 6a).

In general, forward model results are close to measured values. To classify the models according to their ability to fit the empirical acoustic measurements, the difference between each model volume backscattering strength estimate and the corresponding peak of the empirical backscattering data was computed and averaged for all groups of bubble streams (Fig. 6b). Whatever the model, the time-averaged difference between model estimates and empirical results is lower than $3 \mathrm{~dB}$. For the 4 models listed below, the difference is lower than $1 \mathrm{~dB}$ :

- Stanton model for gaseous prolate spheroid with equivalent sphere $\left(n^{\circ} 9\right)$

- Stanton model for gaseous sphere with multiplicative factor $\left(n^{\circ} 5\right)$ 
- Stanton model for gaseous sphere with equivalent sphere $\left(n^{\circ} 8\right)$

- Medwin model for gaseous sphere with multiplicative factor $\left(n^{\circ} 4\right)$

\subsection{Estimation of bubble volumetric flow by inverse modeling of acoustic data}

The principle of inverting acoustic data to derive the volumetric flow of gas bubble releases was investigated from water tank experiments, considering two artificial generated continuous flows of $0.2 \mathrm{l} / \mathrm{min}$ and $0.38 \mathrm{l} / \mathrm{min}$. The acoustic data, provided by a $120 \mathrm{kHz}$ EK-60 echosounder using the horizontal geometry, were processed by the Movies+ software (@) Ifremer). The echo-integration technique, with an echo-integration sampling unit of one minute and an integration window of two meters bounding the bubble echo layer, was applied to measure the mean volume backscattering strength (Sv) of the released bubbles (Fig. 7a).

The bubble volumetric flow values were estimated by the inversion method described in section 2.3 for the four models $(4,5,8$ and 9 ) validated by the forward approach according to the parameters listed in Table 2. Differences among models are less than $1 \mathrm{~dB}$ and volumetric flow results were averaged to simplify the presentation (Fig. 7b).

During the first experiment, the nominal flow of bubbles was set to $0.2 \mathrm{l} / \mathrm{min}$. The measured mean volume backscattering strengths varied between -39.5 and $-35.0 \mathrm{~dB}$ with an average value of $-37.0 \mathrm{~dB}$. The corresponding average bubble volumetric flow estimated by inverse modeling was $0.197 \mathrm{l} / \mathrm{min}$ with a standard deviation of $0.029 \mathrm{l} / \mathrm{min}$.

In the second experiment, the nominal flow was set to $0.38 \mathrm{I} / \mathrm{min}$. Acoustic measurements varied between -36.4 and $-31.8 \mathrm{~dB}$ with an average value of-34.0 dB. Inverse modeling provided an average bubble volumetric flow of $0.384 \mathrm{l} / \mathrm{min}$ with a standard deviation of 0.063 I/min.

These results show the feasibility of estimating bubble volume flows by using the mean volume backscattering strength derived from standard echosounders if the size and shape distribution of the bubbles are known. The observed fluctuations of the averaged volume backscattering strength measurements $(\sim 3 \mathrm{~dB})$ is related to the stochastic process of sound scattering by an ensemble of targets. Even under water tank controlled experiments, the bubble flow was not steady and the fluctuations in backscatter are generated by differences in the number of insonified bubbles, in their position in the acoustic beam and in the orientation and size distributions for a given observation period. A similar behavior can be expected at natural seeps.

\section{Sensitivity analyses}

Sensitivity analysis was used to explore how the outputs (target and volume backscattering strengths) can change with variations in the input parameters of the forward model. The simplest method of one-at-a-time was chosen to illustrate the contribution of each input to the 
output uncertainty. In this approach, one input parameter varies at a time while the others are kept fixed.

Parameter ranges and baseline or nominal values (Table 3) were selected according to ranges of interest for water tank or in situ experiments. Therefore, only a sonar frequency of $120 \mathrm{kHz}$ with horizontal insonification was considered, even though the sensitivity analysis could be used to infer results from other frequencies.

The use of a fixe $120 \mathrm{kHz}$ frequency constrains the sensitivity analysis to a scattering domain away from the resonance for bubble radius larger than $1 \mathrm{~mm}(k a>0.5)$ and the effect of resonant bubbles could be neglected at least for water-depths close to the sea-surface (Fig. 1). Variations of bubble size and behavior along the vertical rising path towards the surface can also be limited when considering the horizontal insonification geometry at a fixed depth (e.g., the half-power diameter of a $7^{\circ}$ acoustic beam is $1.2 \mathrm{~m}$ for a horizontal bubbletransducer distance of $10 \mathrm{~m}$ ) and size changes due to decreasing hydrostatic pressure could be neglected. The physical properties of methane were taken into account even though no differences were observed in backscattered strength of methane and air bubbles at sea-level pressure (Greinert and Nutzel 2004). However, only pure and not hydrate coated gas bubbles were simulated.

\subsubsection{Target strength (TS)}

The sensitivity analysis was performed to observe the impact of bubble depth and size on the backscattering cross-section of a single oblate bubble (Fig. 8). The target strength is almost depth-independent for both Medwin and Stanton equivalent sphere models at $120 \mathrm{kHz}$ in the 0-1500 $\mathrm{m}$ depth range for the given bubble size distribution. As expected, variations of the bubble radius between 1 and $8 \mathrm{~mm}$ can change the target strength by $15 \mathrm{~dB}$ for the Stanton model while the Medwin model is less sensitive to changes in bubble size. This can be explained by the validity of the Stanton « high pass " model for all values of frequencies and size of bubbles. For small values of ka (e.g. low frequency or small size) the Medwin model outperforms the Stanton model to predict the backscatter near the resonance domain.

\subsubsection{Volume backscattering strength $\left(S_{v}\right)$}

The sensitivity analysis was used to explore the behavior of $S_{v}$ estimates according to changes in the distribution values of the following parameters: flow rate, horizontal transducer-to-bubble stream distance, ascent rate of bubbles and bubble size distribution. For simplicity, only results of the Stanton model for gaseous equivalent sphere with a flatness coefficient of 2 are presented, even though differences were observed among models and different bubble flatness coefficients (results not shown).

The estimated $S_{v}$ shows an exponential decrease with transducer-to-bubble stream distance according to $-10 \log$ (distance) (Fig. 9a and 9b). The $S_{v}$ rate of change is high when the bubble source is located in the first tens of meters and decreases for larger distances. The $S_{v}$ value depends on the flow rate even though a constant $S_{v}$ variation of $20 \mathrm{~dB}$ can be observed for every flow rate value within the $0-200 \mathrm{~m}$ distance range. For a $-50 \mathrm{~dB}$ threshold, a weak bubble release $(0.01 \mathrm{l} / \mathrm{min})$ will not be detected beyond $20 \mathrm{~m}$ while a medium $(0.25 \mathrm{l} / \mathrm{min})$ or strong $(0.50 \mathrm{l} / \mathrm{min})$ bubble release could be detected for distances $>200 \mathrm{~m}$. 
The dependence of $S_{v}$ with respect to variations of bubble ascent and flow rates is illustrated in Figures $10 \mathrm{a}$ and $10 \mathrm{~b}$. For a given flow rate, $S_{v}$ shows a negative relationship with the ascent rate of bubbles, but the variation is limited to $\sim 3 \mathrm{~dB}$ within the $15-35 \mathrm{~cm} / \mathrm{s}$ ascent rate range.

The relationship between $S_{v}$ and bubble size within the $0.01-0.5 \mathrm{l} / \mathrm{min}$ flow rate range was investigated by shifting the bubble radius distribution around the average value of $3 \mathrm{~mm}$ (Fig. $11 \mathrm{a}$ and $11 \mathrm{~b}$ ). For every $\pm 1 \mathrm{~mm}$ shifts, the corresponding log-normal fit was computed and then used to estimate the $S_{v}$ value for a given flow rate. Only offset values consistent with the 1-8 $\mathrm{mm}$ bubble radius range were considered. For positive shifts, an error of $\pm 1 \mathrm{~mm}$ in the average radius of the bubble size distribution can induce variations of $\sim 1 \mathrm{~dB}$ in the $S_{v}$. For negative shifts, the $S_{v}$ increases but seems to remain invariant probably due to boundary effects of simulation. For a given flow rate, the inverse relationship between $S_{v}$ and bubble size distribution can be explained as the result of opposite effects of target strength distribution and the number of insonified bubbles. Few large bubbles can hold the same amount of gas as a large number of small bubbles, but the highest target strength values of large bubbles is not sufficient to overcome the decrease in the number of bubbles.

\section{Discussion}

In this study, the feasibility of obtaining an estimation of gas volumes from backscattered signals of rising bubbles detected with a horizontal looking calibrated split-beam echosounder was tested in a sea-water tank controlled experiment. Using target strength modeling and geometric calculation of the number of insonified bubbles within the acoustic beam, the range of volume backscattering strengths $S_{V}$ can be predicted for different target distances according to different bubble size distributions, flow rates and rising speed.

Validity of the method is constrained here by the choice of the 120-kHz frequency and a bubble radius within the 1-8 $\mathrm{mm}$ range which ensures to be far from the specific resonance behavior of gas bubbles in response to a sound pressure field. In basic terms, the target strength of non-resonant spherical bubbles is assumed to increase monotonically with the size distribution.

However, non-spherical gas bubbles can be expected and standard Medwin and Stanton target strength models were modified in this study to consider oblate spheroid targets (ie the equivalent radius of a sphere with the same volume as the oblate spheroid). But, far from resonance, the scattering of non-spherical objects may be strongly affected by the target orientation either for vertical and horizontal insonification geometries. The orientation effect was not considered in this study even though Furusawa (1988) provided a model to compute the angular dependency of target strength of non-spherical objects and the exact solution of the prolate spheroid modal series. For $120 \mathrm{kHz}$ and for the range of bubble size investigated here with a flatness coefficient of 2 , the horizontal target strength can be between 1 and $3 \mathrm{~dB}$ lower than the vertical target strength.

A strong assumption in the forward and inverse methods presented here is that the volume backscattering strength is independent of the position of the bubble stream in the acoustic beam. For horizontal insonification geometry, the bubble or the bubble stream is assumed to 
move upward along a line at the center of the acoustic beam (Fig. 3b). The spatial spreading of bubbles around this line is small with respect to the beam diameter and varies with the volumetric flow input value. This assumption holds for the sea-water tank experiments carried out here with the bubbles always crossing the center of the beam along a vertical line corresponding to the beam width (equations $10 \mathrm{~b}$ or 18). Results from the forward and inverse modeling validation presented in this study are only valid under this condition. For other situations, especially for in situ experiments, when the bubble stream is not located at the center of the beam and the spatial spreading of bubbles is very small compared to the acoustic beam width, the volume backscattering strength will be inaccurate. This situation occurs actually for most configurations for the $7^{\circ}$ beam-width echsosounder for which even at small distance and large flow rates the bubble plumes occupies less than $10 \%$ of the beam width. To compensate the volume backscattering strength for this effect, the position of the bubble stream in the across beam width should be known which can only be inferred from split-beam transducer phase measurements.

The main advantage of split-beam echosounders is to account for the beam directivity effects in backscatter measurements. Split-beam echosounders can be useful for in situ monitoring of gas vents for three reasons.

First, it allows implementing the standard method for echosounder calibration with a reference target (Foote et al, 1987) by measuring the transducer on-axis sensitivity and the form function of the beam pattern. Calibration is carried out by fully positioning the reference target using interferometric processing. The form function of the beam pattern can then be compensated to provide accurate volume backscattering measurements.

In this study, the calibration of the $120 \mathrm{kHz}$ split-beam echosounder was done in the water tank and valid for depths close to the surface and for the data presented here. Recent studies show a variation of echosounder-transducer performance with changes in temperature or in depth/pressure. For similar $120 \mathrm{kHz}$ echosounders, the gain can vary by $\sim 1$ $\mathrm{dB}$ for water temperatures ranging from $1{ }^{\circ} \mathrm{C}$ to $18^{\circ} \mathrm{C}$ at sea level atmospheric pressure (Demer and Renfree 2008) and the overall on-axis TS can vary by $3 \mathrm{~dB}$ for water depths ranging from sea-surface to $800 \mathrm{~m}$ with local variations of $0.7 \mathrm{~dB}$ at the depth of $800 \mathrm{~m}$ (Ryan et al. 2009). For in situ experiments, the calibration function of split-beam echosounders could be used to collect referenced target data according to local depth and temperature values and to test regularly the performance of the equipment.

The second application commonly used in fisheries acoustics also relies on the ability to measure the along and across beam angular positions of a single object to accurately determine its target strength. This only applies here for low bubble flow rates or for measurements in the outside edge of bubble streams where single bubbles can be detected. The bubble size distribution can be estimated by the TS inversion function and assumed to represent a proxy of the true size distribution. The limits of the method are obvious. Small non resonant bubbles (radius $<\sim 0.5 \mathrm{~mm}$ ) could not be detected for low signal-to-noise ratios. Two or more bubbles located at the same distance from the transducer will not be resolved by the target strength algorithm. Coalescent bubbles can be detected as a single large one with strong TS value.

Despite these bias and uncertainties, size distributions derived from $120 \mathrm{kHz}$ split-beam target strength measurements could still be useful when video data is not available or of poor quality. It would be useful for in situ continuous monitoring because acoustic detection 
ranges are in tens of meters and several space-resolved bubble sources can be investigated at the same time while video detection is limited to few meters.

A multifrequency approach might be useful to estimate the size distribution of bubbles. Backscattered signals usually provided by split-beam transducers within the $18-333 \mathrm{kHz}$ frequency range are mainly used in fisheries and plankton acoustics (Simmonds and MacLennan 2005) to discriminate groups of biological targets well separated in sizes (e.g., Trenkel and Berger 2013) or to estimate the abundance of zooplankton according to size and shape (e.g., Lebourges et al. 2009). Ground thruthing of acoustic data, model parameterization tuning and environment characterization are performed along the survey with biological samples and multi-sensors vertical profiles. Low frequency and broadband techniques are also used in fisheries (for a wide review see Stanton et al. 2012) to discriminate groups of different resonant-sized organisms. Beyond operational constraints or environmental issues for autonomous in situ monitoring, further investigations should be carried out to estimate the contribution and limits of these techniques for relatively homogeneous targets narrowed distributed within about $10 \mathrm{~mm}$ ranges as bubbles escaping from seafloor seeps. A possible interest would be their discrimination power when bubbles and biological echoes coexist in the same environment.

The third application of split-beam echosounders is the possibility of using the across-beam phase information to locate a bubble stream in the beam pattern in the case of horizontal insonification. For the experiments carried out in the water tank, the phase information was only used to verify the on-axis location of the bubble stream where the insonified stream length corresponds to the beam diameter. For in situ experiments, randomly across-beam stream locations can be expected which has not been considered by the numerical solutions presented here. Bubble stream location can be used to compute the attenuation of the backscattered signal due to the beam-pattern and the actual insonified bubble stream height (Fig 12a). $S_{v}$ attenuation can vary by $\sim 8 \mathrm{~dB}$ for across beam angles ranging from 0 (center of the beam) to \pm 3 degrees. This alternative method was used to compute the detection probability of a bubble stream for a given $S_{v}$ threshold from a large number of $S_{v}$ values corrected for a random angular attenuation (Fig. 12b). Further work will be carried out to test the detection probability plot with field experimental data.

A last advantage of using echosounders originally designed for fishery applications is their ability to monitor a wide scattering range from weak scatterers as fluid like plankton organisms to strong scatterers as the seafloor echo. This specificity is achieved through side lobe suppressions (Trenkel et al 2008) that avoid ghost echoes from targets that backscatter sound from the side lobe of the beam. In this study, it was shown that the Sv values range from -20 to $-70 \mathrm{~dB}$ depending on flow rate, distance and position of the bubble stream. Such dynamic of signal requires side lobe suppression as low as $50 \mathrm{~dB}$ in order to avoid false detection from the side lobes of a strong scatterer located at the same range as a weak scatterer.

Experimental and theoretical results of this study are only related to free gas bubbles, without considering effects of hydrate skin formation in the bubble size and shape distributions or in the backscattering. Hydrated coated bubbles are more spherical than free gas bubbles (Rehder et.al 2002, 2009; Bigalke et al 2010) and can be found within the hydrate stability field according to the pressure-temperature profile of an in situ experiment. Rising velocities may also be different and hydrate coated bubbles appear to rise at lower velocities than equally sized but more deformed bubbles (Bigalke et al. 2010). Differences in backscattering properties (density ratio and sound speed ratio) might be expected between hydrate skin 
coated and free gas bubbles and target strength relationships will differ. Several studies report ship-board acoustic observation of flares within the hydrate stability field (e.g., McGinnis et al. 2006; Sauter et al. 2006; Foucher et al. 2010), however it is difficult to derive accurate acoustic measurements of sources located at water depths $>\sim 250 \mathrm{~m}$ and to decorrelate the combined acoustic-physical process affecting the backscattered signals of rising bubbles towards the surface.

Bubble shrinkage and bubble expansion along the rising path were not considered in this study. It was assumed that during the time interval required for bubbles to cross the beam, these behaviors could be neglected according to bubble ascent rate and size ranges studied here. The time taken for a bubble located $100-\mathrm{m}$ far from the echosounder to cross the beam diameter $(12.2 \mathrm{~m})$ at $30 \mathrm{~cm} / \mathrm{s}$ is 40 seconds which is relatively fast compared to time scale of shrinkage process which is in minutes (Bigalke et al. 2010). However, this issue should be further investigated and eventually integrated in the model.

\section{Summary and conclusions}

The feasibility of monitoring gas bubble releases with a $120 \mathrm{kHz}$ split-beam echosounder and horizontal insonification geometry was tested in sea-water tank experiments. Experimental data were used to validate the forward and inverse modeling approaches through a modified echo-integration numerical solution for the horizontal insonification geometry and for line bubble streams not occupying the entire insonification volume. The forward volume backscattering strength is in good agreement with experimental data within differences of $\sim 1$ $\mathrm{dB}$ among the four best fit models. The inversion volumetric flow rate solutions were also in good agreement with flow rates of 0.2 and $0.38 \mathrm{l} / \mathrm{min}$. Validation of the forward and inverse modeling holds for the experiments presented here where input parameters are known and uncertainties reduced to minimum. A sensitivity analysis was carried out to investigate the behavior of the $120-\mathrm{kHz}$ forward solution with respect to model input parameters (horizontal distance between transducer and bubble stream, bubble size distribution and ascent rate). The most sensitive parameter was found to be the distance of the bubble stream which can affect the volume backscattering strength by $20 \mathrm{~dB}$ within the horizontal range of 0 to $200 \mathrm{~m}$ and for flow rates varying between 0.01 and $0.5 \mathrm{l} / \mathrm{min}$. Results were used to derive the detection probability of a bubble stream for a given volume backscattering strength threshold according to different bubble flow rates and horizontal distances.

Further work is required for in situ validation of the methods presented here. The experimental set up should be carefully designed to provide the most accurate information on the input parameters required for volume backscattering strength inversion including bubble size and shape distributions, bubble ascent rate, physical properties of bubbles (gas composition, hydrate coated or not), spatial spreading of the bubble release at the insonification distance, environmental characterization. Echosounder in situ calibration should also be considered. Experimental set ups like this are vessel consuming and implies the use of multiple sensors and sampling techniques, some of them only deployed with the help of ROV. Even though, only a limited number of insonified bubble seeps could be sampled according to this experimental design, broad ground thruthing of different bubble seeps would largely be useful to validate inversion acoustic methods.

Meanwhile, in situ volume backscattering strengths can still be used to observe relative temporal variations with a calibrated echosounder. Confidence intervals could be derived from the sensitivity analysis of $S_{v}$ with respect to the most important control variables including position of the seep in the beam and applied to observed effective temporal variations. 


\section{Nomenclature}

a: radius of bubble

$n(a)$ : concentration of bubbles per classes of radii

$k$ : acoustic wave number

$f_{0}$ : resonance frequency of bubble

$s_{v}$ : volume backscattering coefficient $\left(\mathrm{m}^{-1}\right)$

$S_{v}$ : volume backscattering strength $\left(\mathrm{dB} r e \mathrm{~m}^{-1}\right)$

$\sigma_{b s}:$ acoustic backscattering cross-section $\left(\mathrm{m}^{2}\right)$

$T S$ : target strength $\left(\mathrm{dB}\right.$ re $\left.1 \mathrm{~m}^{2}\right)$

$z$ : depth

$V_{\text {ascent: }}$ ascent rate of bubbles

$F_{v}$ : bubble volumetric flow

$N_{t}$ : number of bubbles of radius a per time unit

$N_{m}$ : number of bubbles per meter

$N_{i}$ : number of bubbles in the integrated volume

l: integration bin width

$V_{i \text { : }}$ echo-integrated sampling volume

$R$ : beam radius 


\section{Acknowledgements}

The authors thank the members of Testing Pool Facilities and Technological Research Unit of Ifremer for their help during experiments in water tank. The authors thank the members of Marine Geoscience Research Unit of Ifremer who also contributed to this work. The authors thank IRD/LEMAR acoustic team for their support during some experiments. Part of this paper reports post-doctoral work of I. Leblond funded by TOTAL.

\section{References}

Anderson VC (1950) Sound Scattering from a Fluid Sphere.J. Acoust. Soc. Am. Vol. 22. (4) Artemov YG, Egorov VN, Polikarpov GG, Gulin SB Kovalevsky AO (2007) Methane emission to the hydro- and atmosphere by gas bubble streams in the Dnieper paleo-delta, the Black Sea. Rep. Natl. Acad. Sci. Ukraine 5: 110-116.

Bigalke NK, Enstad LI, Rehder G, Alendal G (2010) Terminal velocities of pure and hydrate coated $\mathrm{CO} 2$ droplets and $\mathrm{CH} 4$ bubbles rising i a simulated oceanic environment. DeepSea Researc I 57: 1102-1110.

Clay CS, Horne JK (1994) Acoustic models of fish: The Atlantic cod (Gadusmorhua). J. Acoust. Soc. Am. 96 (3).

Clift, R., Grace, J., Weber, M. (1978). Bubbles, Drops, and Particles. Academic Press, New York.

Demer DA and Renfree JS (2008) Variations in echosounder-transducer performance with water temperature. ICES. J. Mar. Sci. 65: 1021-1035.

Dupré S, Berger L, Le Bouffant N, Scalabrin C, Bourillet J-F. Fluid emissions at the Aquitaine Shelf (Bay of Biscay, France): a biogenic origin or the expression of hydrocarbon leakage? In revision, Continental Shelf Research.

Fleischer P, Orsi TH, Richardson MD, Anderson AL (2001) Distribution of free gas in marine sediments: a global overview. Geo-Mar Lett 21: 103-122.

Foote KG, Knudsen HP, Vestnes G, MacLennan DN, Simmonds EJ (1987) Calibration of acoustic instruments for fish density estimation: a practical guide. ICES Cooperative Research Report, 144.

Foucher J-P, Dupré S, Scalabrin C, Feseker T, Harmegnies F, Nouze H (2010). Changes in seabed morphology, mud temperature and free gas venting at the Hakon Mosby mud volcano, offshore northern Norway, over the time period 2003-2006. DI 10.1007/s00367010-0193-z. Geo-Marine Letters, 30 (3-4): 157-167.

Furusawa M (1988) Prolate spheroidal models for predicting general trends of fish target strength. J Acoust Soc Jpn 9: 13-24.

Géli L, Henry P, Zitter T, Dupré S, Tryon M, Cagatay MN, Mercier de Lépinay B, Le Pichon X, Sengör AMC, Görür N, Natalin B, Uçarkus G, Ozeren S, Volker D, Gasperini L, Bourlange S, the Marnaut Scientific Party (2008) Gas emissions and active tectonics within the submerged section of the North Anatolian Fault zone in the Sea of Marmara. Earth and Planetary Science Letters 274(1-2): 34-39

Greinert J and Nützel B (2004) Hydroacoustic experiments to establish a method for the determination of methane bubble fluxes at cold seeps. Geo-Mar Lett 24: 75-85.

Greinert J, Artemov Y, Egorov V, De Batist M, McGinnis D (2006) 1300-m-high rising bubbles from mud volcanoes at $2080 \mathrm{~m}$ in the Black Sea: Hydroacoustic characteristics and temporal variability. Earth and Planetary Science Letters 244: 1-15

Greinert, J. (2008) Monitoring temporal variability of bubble release at seeps: The hydroacoustic swath system GasQuant. Journal of Geophysical Research, 113, C07048

Hsu SK, Wang SY, Liao YC, Yang TF, Jan S (2013) Tide-modulated gas emissions and tremors off SW Taiwan. Earth and Planetary Science Letters 369-370: 98-107 
Johnson RK (1977) Sound scattering from a fluid sphere revisited J. Acoust. Soc. Am. 61 (2): 375-377 and "Erratum: 'Sound scattering from a fluid sphere revisited,' "J. Acoust. Soc. Am. 63 (2) 553-564.

Judd AG (2004) Natural seabed gas seeps as sources of atmospheric methane. Environmental Geology 46: 988-996.

Judd AG, Hovland M (2007) Seabed Fluid Flow. Cambridge University Press, New York, 360 $\mathrm{pp}$

Lebourges-Dhaussy A, Coetzee J, Hutchings L, Roudaut G, Nieuwenhuys C (2009) Zooplankton spatial distribution along the South African coast studied by multifrequency acoustics, and its relationships with environmental parameters and anchovy distribution. ICES. J. Mar. Sci., 66: 1055-1062

Leifer I, de Leeuw G, Leo H, Cohen L H (2003) Optical Measurement of Bubbles: System Design and Application. J. Atmos. Oceanic Technol. 20: 1317-1332.

Leifer I (2010) Characteristics and scaling of bubble plumes from marine hydrocarbon seepage in the Coal Oil Point seep field. Journal of Geophysical Research 115 C11014, doi:10.1029/2009JC005844.

Lurton X (2002) An Introduction to Underwater Acoustics. Principles and Applications. Praxis Publishing Ltd, Chichester, UK.

McGinnis DF, Greinert J, Artemov Y, Beaubien SE, Wuest A (2006) Fate of rising methane bubbles in stratified waters: How much methane reaches the atmosphere? Journal of Geophysical Research, VOL. 111, C09007, doi:10.1029/2005JC003183

Medwin H and Clay CS (1998) Fundamentals of Acoustical Oceanography. Academic Press, San Diego. $712 \mathrm{pp}$

Nikolovska A, Sahling H, Bohrmann G (2008) Hydroacoustic methodology for detection, localization, and quantification of gas bubbles rising from the seafloor at gas seeps from the eastern Black Sea.Geochemistry Geophysics Geosystems 9(10).

Ostrovsky I, McGinnis DF, Lapidus L, Eckert W (2008) Quantifying gas ebullition with echosounder: the role of methane transport by bubbles in a medium-sized lake. Limnol. Oceanogr.: Methods 6: 105-118.

Paull CK, Ussler W, Borowski WS, Spiess FN (1995) Methane-rich plumes on the Carolina continental rise : associations with gas hydrates. Geology 23 (1): 89-92.

Rehder G, Brewer PW, Peltzer ET, Friederich G (2002) Enhanced lifetime of methane bubble streams within the deep ocean. Geophys. Res. Let 29(15) 1731.

Rehder G, Leifer I, Brewer PG, Friederich G, Peltzer ET (2009) Controls on methane bubble dissolution inside and outside the hydrate stability field from open ocean field experiments and numerical modelling. Marine Chemistry 114: 19-30

Rona P-A, Palmer DR, Jones C, Chayes DA, Czarnecki M, Carey EW, Guerrero JC, (1991) Acoustic Imaging of Hydrohermal Plumes, East Pacific Rise, $21^{\circ} \mathrm{N}, 109^{\circ} \mathrm{W}$. Geophys. Res. Let 18: 2233-2236

Ruhl HA, André M, Beranzoli L, Cagatay MN, Colaco A, Cannat M, Danobeitia JJ, Favali P, Geli L, Gillooly M, Greinert J, Hall POJ, Huber R, Karstensen J, Lampitt RS, Larkin KE, Lykousis V, Mienert J, Miranda JM, Person R, Priede IG, Puillat I, Thomsen L, Waldmann C (2011) Societal need for improved understanding of climate change, anthropogenic impacts, and geo-hazard warning drive development of ocean observatories. European Seas. Progress In Oceanography 91(1): 1-33.

Ryan TE, Kloser RJ, Macaulay GJ (2009) Measurement and visual verification of fish target strength using an acoustic-optical system attached to a trawlnet. ICES. J. Mar. Sci. 66 (6): 998-1006.

Sauter EJ, Muyakshin SI, Charlou JL, Schlüter M, Boetius A, Jerosch K, Damm E, Foucher JP and Klages M (2006) Methane discharge from a deep-sea submarine mud volcano into the upper water column by gas hydrate-coated methane bubbles. Earth and Planetary Science Letters 243(3-4): 354-365.

Schneider von Deimling J, Brockhoff J, Greinert J (2007) Flare imaging with multibeam systems: Data processing for bubble detection at seeps. Geochemistry Geophysics Geosystems Technical Brief 8 (6) 
Simmonds JE, MacLennan DN (2005) Fisheries Acoustics. Blackwell Publishing

Stanton TK (1989) Simple approximate formulas for backscattering of sound by spherical and elongated objects. J. Acoust. Soc. Am 86 (4)

Stanton TK, Sellers CJ, Jech JM (2012) Resonance classification of mixed assemblages of fish with swimbladders using a modified commercial broadbanc acoustic echosounder at 1-6 kHz. Can. J. Fish. Aquat. Sci. 69: 854-868

Tang D (1996) Modeling high-frequency acoustic backscattering from gas voids buried in sediments. Geo-Marine Letters 16 (3)

Trenkel, V. M., Mazauric, V., and Berger, L. 2008. The new fisheries multibeam echosounder ME70: description and expected contribution to fisheries research. ICES Journal of Marine Science, 65: 645-655.

Trenkel V, Berger L (2013) A fisheries acoustic multi-frequency indicator to inform on large scale spatial patterns of aquatic pelagic systems. Ecological Indicators 30: 72-79. http://dx.doi.org/10.1016/j.ecolind.2013.02.006

Westbrook GK, Thatcher KE, Rohling EJ, Piotrowski AM, Pälike H, Osborne AH, Nisbet EG, Minshull TA, Lanoisellé M, James RH, Huhnerbach V, Green D, Fisher RE, Crocker AJ, Chabert A, Bolton C, Beszczynska-Möller A, Berndt C, Aquilina A (2009) Escape of methane gas from the seabed along the West Spitsbergen continental margin. Geophysical Research Letters 36(15) L15608. 
Table 1 Schematic scaled views of the theoretical oblate bubble, with semi-major axis $a$ of 2 $\mathrm{mm}$ and semi-minor axis $b$ of $1 \mathrm{~mm}$ and the corresponding modified spheres (left column, see section 2.1) used to compute target strength values as a function of theoretical oblate bubble size for each model using a frequency of $120 \mathrm{kHz}$. Flatness coefficient $(a / b)$ of the bubble is constant and equal to 2 .

\begin{tabular}{|c|c|c|c|}
\hline Bubble shape & $\begin{array}{l}\text { Medwin (gaseous } \\
\text { sphere) }\end{array}$ & $\begin{array}{c}\text { Stanton (gaseous } \\
\text { sphere) }\end{array}$ & $\begin{array}{l}\text { Stanton (gaseous } \\
\text { prolate spheroids) }\end{array}$ \\
\hline $\begin{array}{l}\text { Radius equal to the } \\
\text { semi-major axis }\end{array}$ & 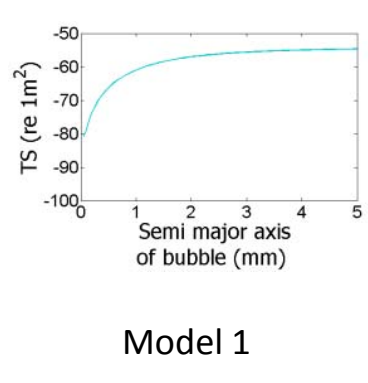 & 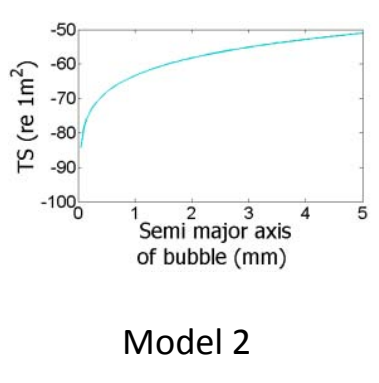 & 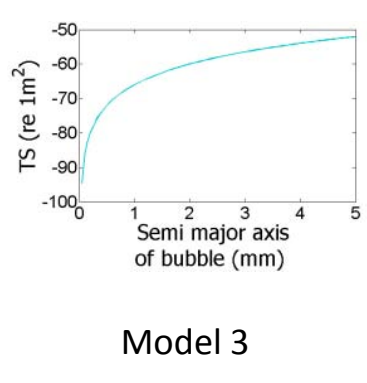 \\
\hline $\begin{array}{l}\text { Radius equal to the } \\
\text { semi-minor axis with } \\
\text { multiplicative factor on } \\
\mathrm{S}_{\mathrm{V}}(1.84 \text { in this example) }\end{array}$ & 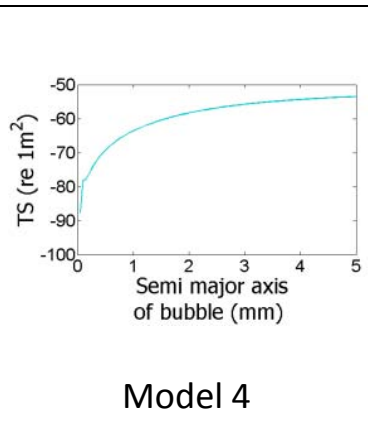 & 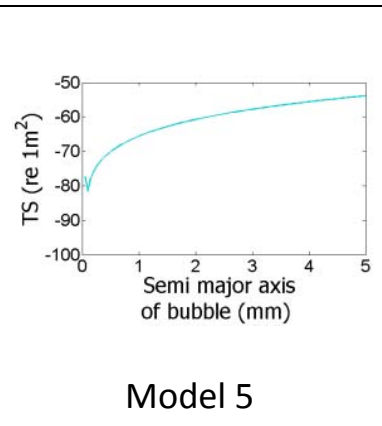 & 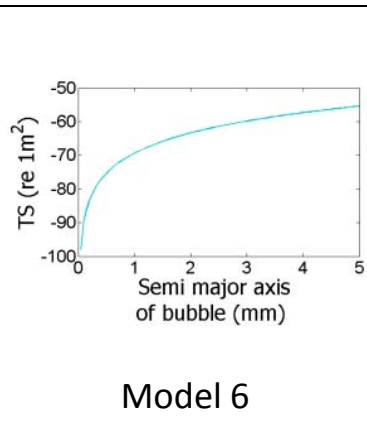 \\
\hline$\underbrace{0}_{-2-2 \text { bubble size }(\mathrm{mm})}$ & 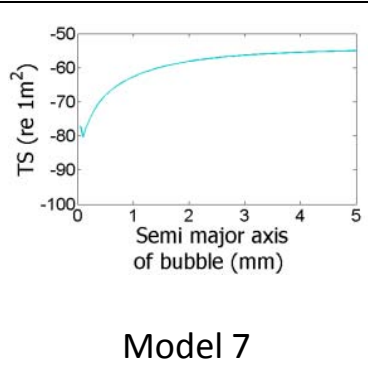 & 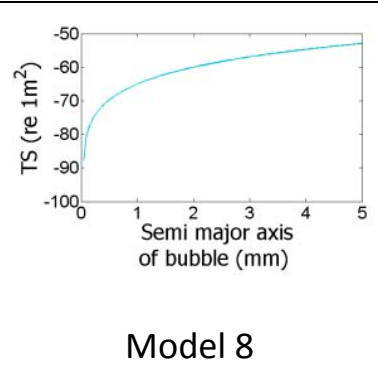 & 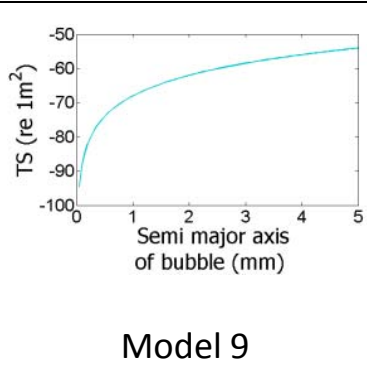 \\
\hline
\end{tabular}


Table 2 Parameters values used for the forward and inverse modeling (water tank experiments data).

\begin{tabular}{|c|c|c|}
\hline \multirow{2}{*}{$\begin{array}{l}\text { Input } \\
\text { parameters }\end{array}$} & \multicolumn{2}{|c|}{ Water tank experiments } \\
\hline & Forward modeling & Inverse modeling \\
\hline Frequency $(\mathrm{kHz})$ & 200 & 120 \\
\hline Beam angle $2 \theta_{3}$ (degree) & 7 & 7 \\
\hline $\begin{array}{l}\text { Transducer-to-bubble } \\
\text { distance }(\mathrm{m})\end{array}$ & 15 & 12 \\
\hline $\begin{array}{l}\text { Altitude of the bubble } \\
\text { stream when crossing } \\
\text { the center of the acoustic } \\
\text { beam }(m)\end{array}$ & 5.6 & 7.3 \\
\hline $\begin{array}{l}\text { Integrated layer width } \\
\text { (m) }\end{array}$ & 0.38 & 2 \\
\hline $\begin{array}{l}\text { Volume backscattering } \\
\text { strength }\left(\mathrm{dB} \text { re } 1 \mathrm{~m}^{-1}\right)\end{array}$ & Estimated output & $\begin{array}{c}\text { Measurements } \\
1^{\text {st }} \text { experiment: } S v=[-39.5 ;-35], \\
\text { mean value: }-37 \mathrm{~dB} \\
2^{\text {nd }} \text { experiment: } S v=[-36.4 ;-31.8] \\
\text { mean value: }-34 \mathrm{~dB}\end{array}$ \\
\hline $\begin{array}{l}\text { Sea water density } \\
\left(\mathrm{kg} \mathrm{m}^{-3}\right)\end{array}$ & 1030 & 1030 \\
\hline $\begin{array}{l}\text { Acoustic wave velocity in } \\
\text { sea water }\left(\mathrm{m} \mathrm{s}^{-1}\right)\end{array}$ & 1500 & 1500 \\
\hline Gas density $\left(\mathrm{kg} \mathrm{m}^{-3}\right)$ & 1.2 & Air \\
\hline Heat capacity ratio & 1.4 & Air \\
\hline $\begin{array}{l}\text { Bubbles size range (semi- } \\
\text { major axis, } \mathrm{mm} \text { ) }\end{array}$ & {$[0-10]$} & {$[0-10]$} \\
\hline $\begin{array}{l}\text { Shape of bubble size } \\
\text { distribution (video data) }\end{array}$ & $\begin{array}{l}\text { Mode value of the radius } \\
\text { distribution }=2.74 \mathrm{~mm} \\
\text { Parameters of log-normal fit : } \\
\mu=1.14, \sigma=0.32 \\
\text { Maximum }=2.85 \mathrm{~mm}\end{array}$ & $\begin{array}{l}\text { Mode value of the radius distribution } \\
1.65 \mathrm{~mm} \\
\text { Parameters of log-normal fit : } \\
\mu=0.78, \sigma=0.55 \\
\text { Maximum }=1.62 \mathrm{~mm}\end{array}$ \\
\hline $\begin{array}{l}\text { Bubble flatness } \\
\text { coefficient }\end{array}$ & $\begin{array}{r}\text { Logarithmic } f \\
\text { Flatness value } \\
\end{array}$ & $\begin{array}{l}\text { t of video data. } \\
\text { interval : }[1-2.5]\end{array}$ \\
\hline $\begin{array}{l}\text { Bubble ascent rate } \\
\left(\mathrm{cm} \mathrm{s}^{-1}\right)\end{array}$ & 31.6 & 15.4 \\
\hline $\begin{array}{l}\text { Volumetric flow of gas } \\
\text { bubbles }\left(I \mathrm{~min}^{-1}\right)\end{array}$ & $\begin{array}{l}\text { Computed from video pictures } \\
\text { Co.002 } \\
\text { according to the total number of } \\
\text { bubbles for every stream }\end{array}$ & Estimated output \\
\hline
\end{tabular}


Table 3: Range interval and fixed values of input parameters used in the sensitivity analysis of the forward modeling approach

\begin{tabular}{|l|l|l|}
\hline In put parameter & $\begin{array}{l}\text { Range interval } \\
\text { [minimum:step:maximum] }\end{array}$ & Fixed value \\
\hline Bubble radius or semi-major axis $(\mathrm{mm})$ & $\begin{array}{l}{[1: 0.5: 8]} \\
\text { Log-normal distribution }\end{array}$ & $\begin{array}{l}3 \\
\text { Log-normal distribution }\end{array}$ \\
\hline Ascent rate $\left(\mathrm{m} \mathrm{s}^{-1}\right)$ & {$[0.15: 0.01: 0.35]$} & 0.27 \\
\hline Bubble source depth $(\mathrm{m})$ & {$[10: 10: 1500]$} & 10 \\
\hline Horizontal transducer-target distance $(\mathrm{m})$ & {$[1: 1: 200]$} & 50 \\
\hline Volumetric flow of gas bubbles $\left(\mathrm{Imin}^{-1}\right)$ & {$[0.01: 0.01: 0.5]$} & 2 \\
\hline Flatness & & 120 \\
\hline Frequency $(\mathrm{kHz})$ & & - \\
\hline
\end{tabular}




\section{Figures}

Fig. 1 Target strength values computed by Medwin and Stanton formulae for gas-filled spheres and Stanton formula for gas-filled prolate spheroids, as a function of bubble radius $(120 \mathrm{kHz})$

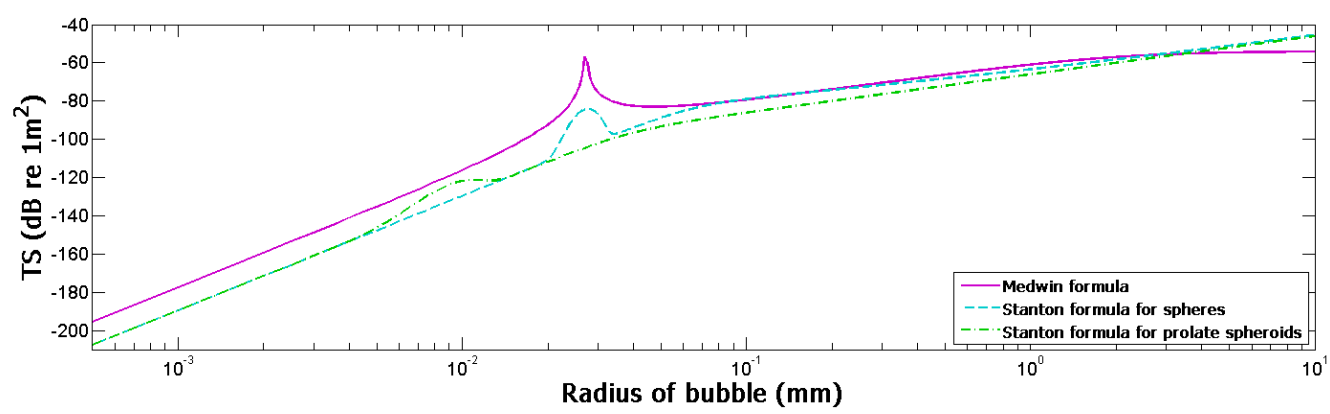

Fig. 2 a Picture of air bubbles in the water used to illustrate their oblate shape (photo Ifremer February 2009) b Oblate spheroid as an approximation of bubble shape
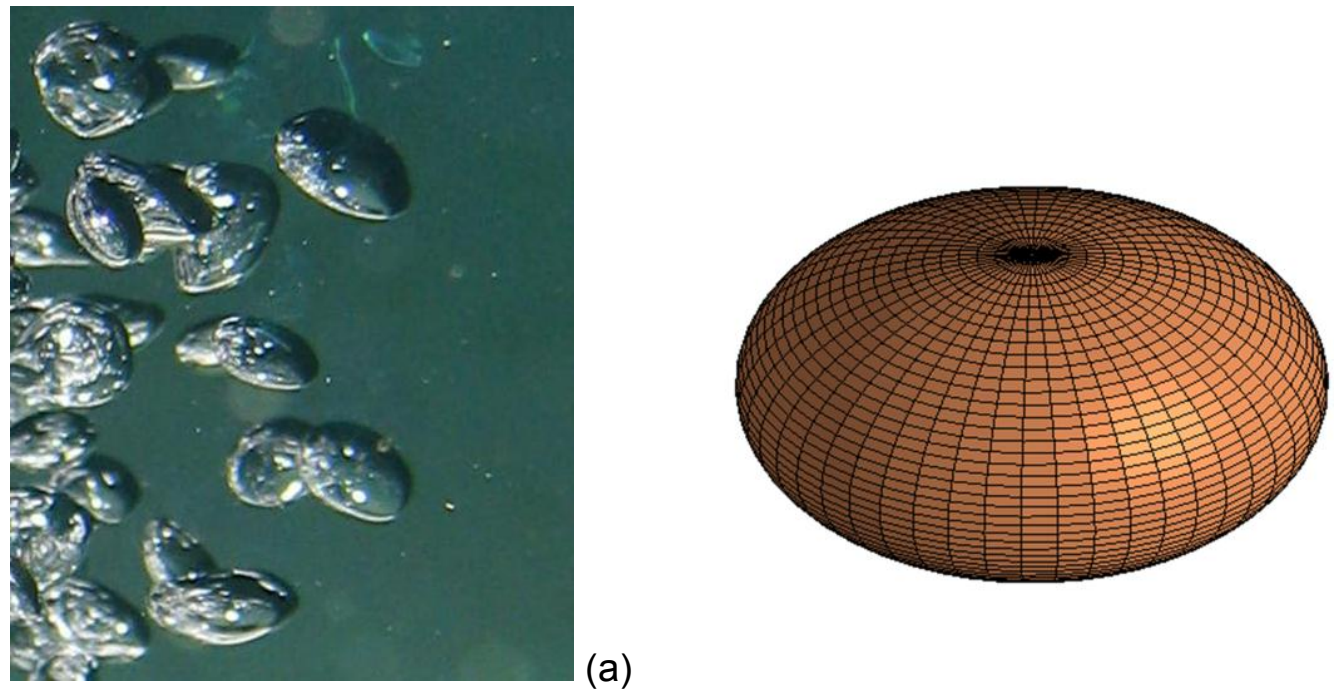

(b)

(a) 
Fig. 3 Schematic 3D view of vertical (a) and horizontal (b) geometries for acoustic bubble release observation. In the $3 \mathrm{D}$ boxes, the yellow cone represents the acoustic beam, the red rectangle is the transducer position and black dots are bubbles. Rightward yellow circles correspond to the beam surface and the instantaneous position of the insonified bubbles at a given distance from the transducer. The bubble stream may be detected all along the acoustic beam with the vertical geometry, in contrast, when using the horizontal geometry, the bubble stream is only detected while crossing the acoustic beam during its rising towards the surface

(a)
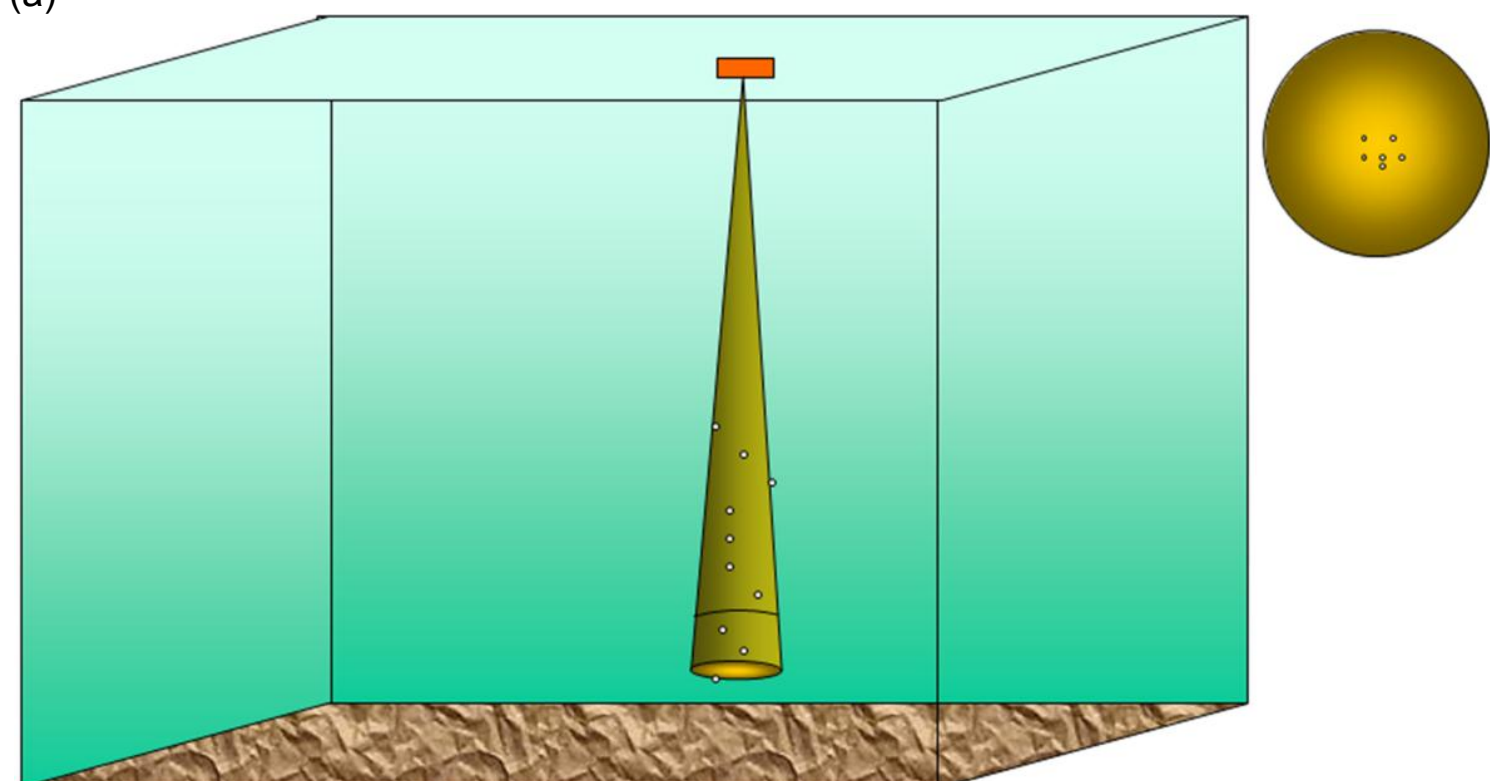

(b)

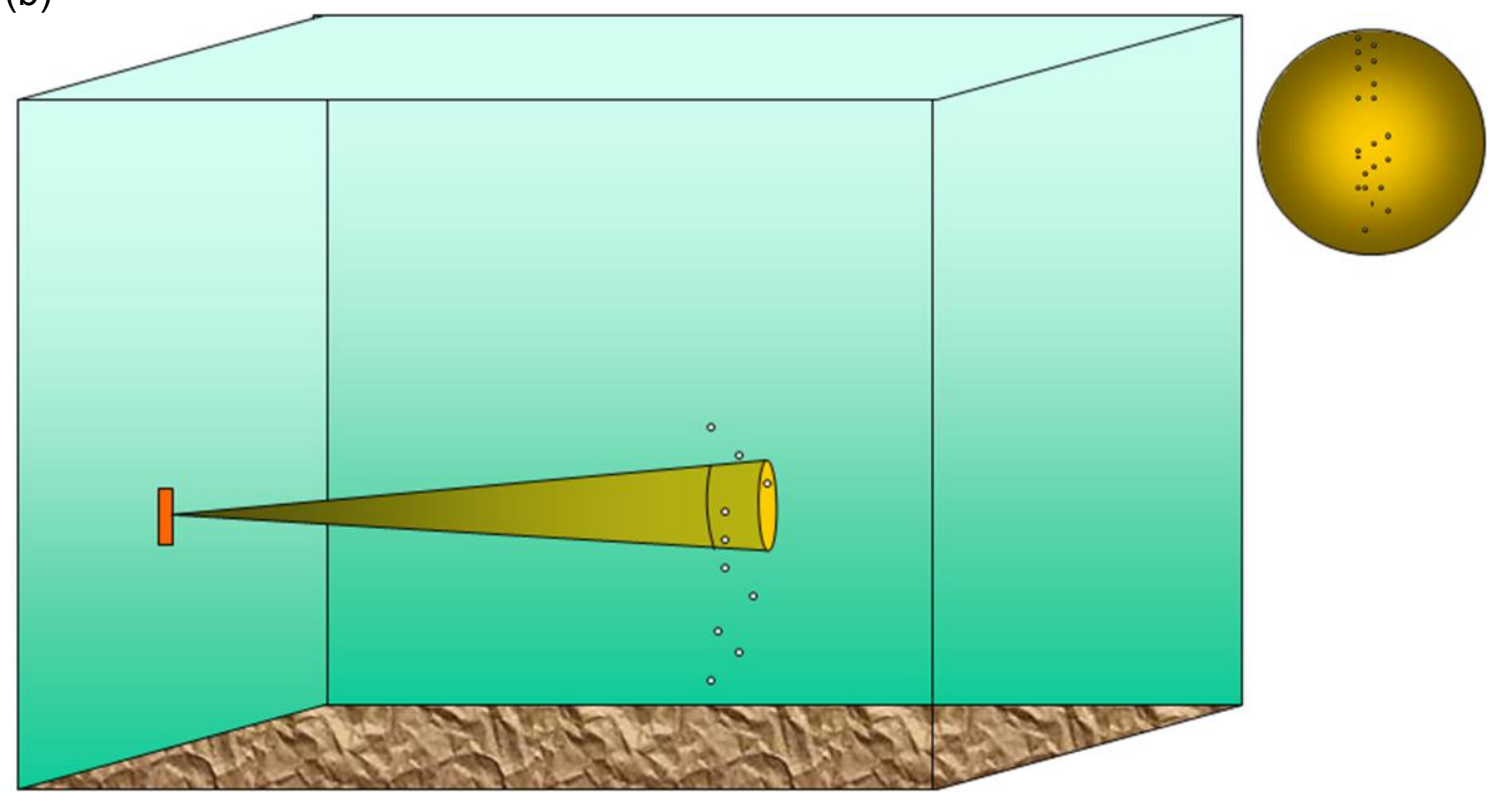


Fig. 4 a Histogram of bubble semi-major axis derived from water tank video pictures for one experiment and log-normal fit equation $(\mu=1.14, \sigma=0.32$, Maximum $=2.85 \mathrm{~mm}$ ) b Scatter plot of flatness and bubble semi-major axis values and logarithmic fit of the data (i.e. linear fit using logarithmic values of semi-major axis and linear values of flatness, equation of the flatness curve for these data is $f=0.45+1.4 \times \log$ (a) with a semi-major axis of bubble in $\mathrm{mm})$

(a)

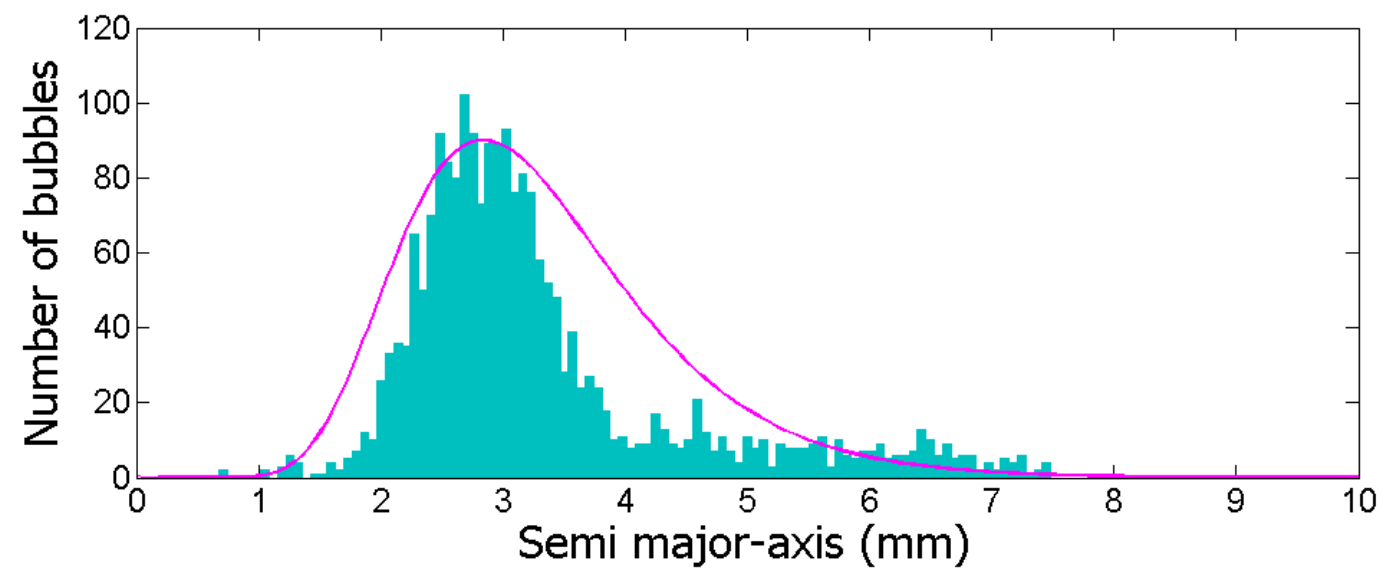

(b)

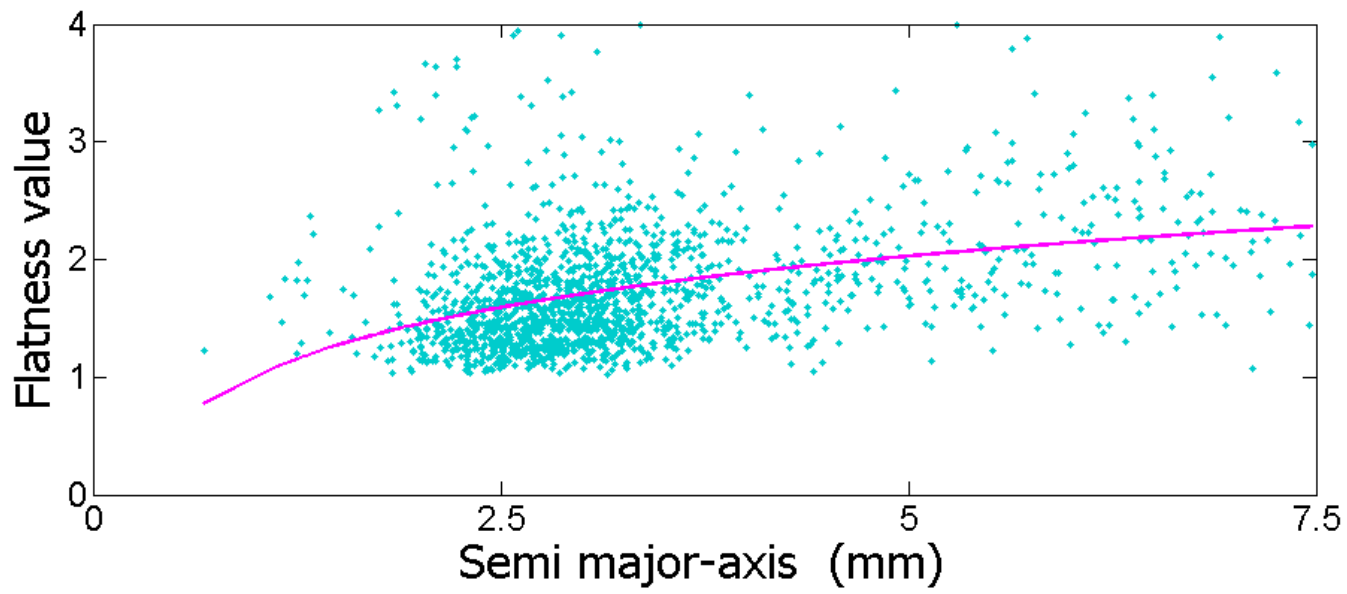


Fig. 5 a Video picture examples of intermittent bubble streams $\mathbf{b}$ Expanded view echogram of bubble echoes generated by an artificial and intermittent bubble source located on the water tank floor during 18 minutes ( $y$-axis express the horizontal distance between transducer and echoes, color bar represents the volume backscattering strength in decibels)

(a)

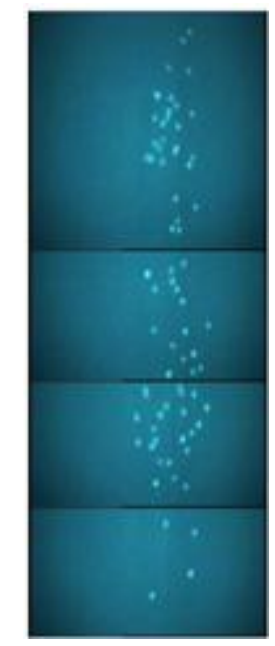

(b)

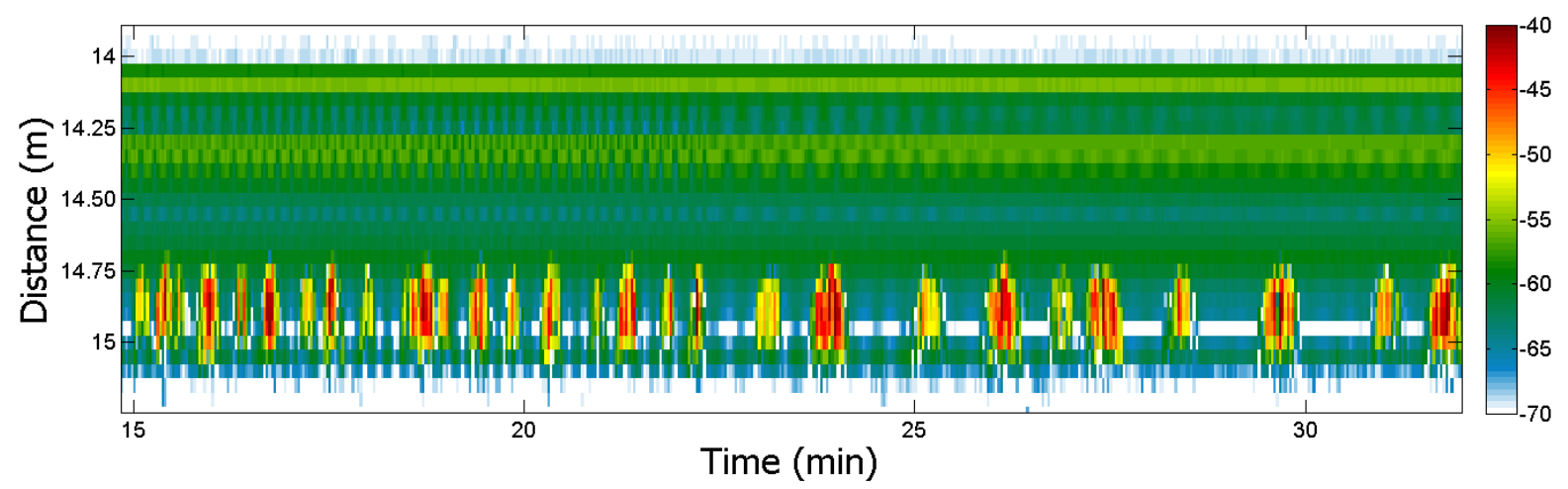


Fig 6 Results of the forward modeling a Comparison between volume backscattering strength measurements $\left(\mathrm{S}_{\mathrm{V}}\right)$ plotted as a function of time and volume backscattering strength values computed by forward models for each artificially generated bubble cluster. b Average difference between measurements and computed results for each model (see text and Table 1 for model number correspondence)

(a)

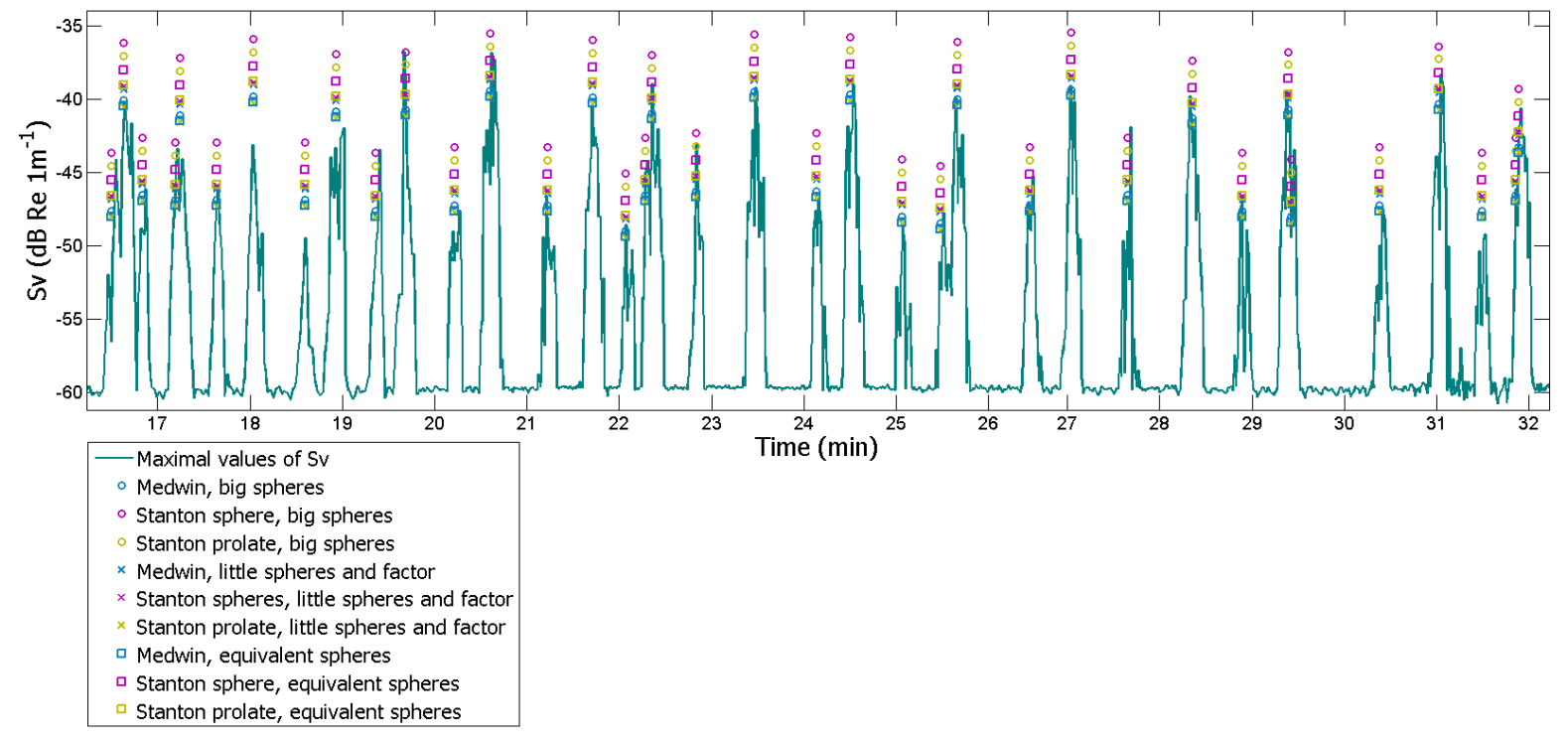

(b)

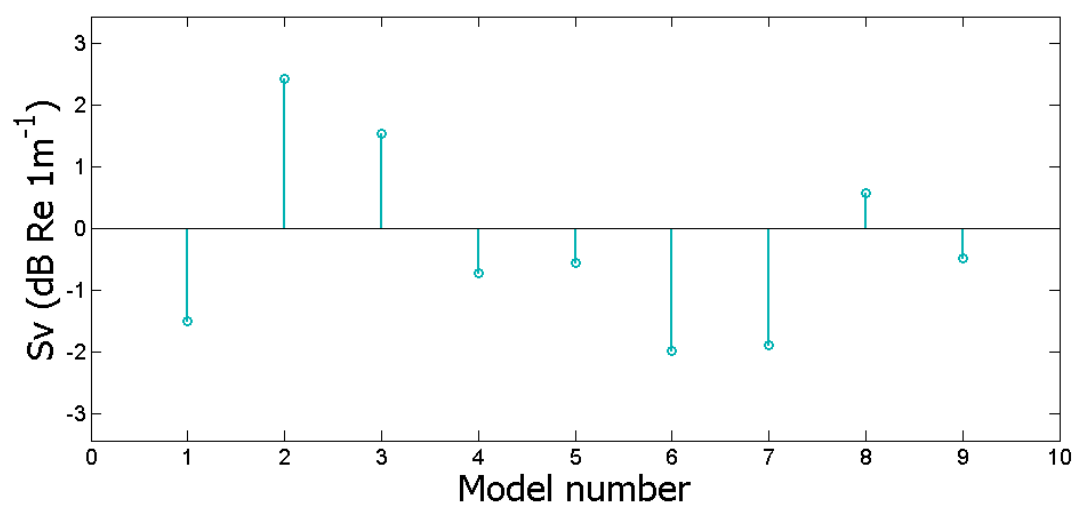


Fig. 7 Results of inverse modeling a Time series of measured volume backscattering strength for volumetric flows of $0.2 \mathrm{l} / \mathrm{min}$ (left part of the curve) and $0.38 \mathrm{l} / \mathrm{min}$ (right part of the curve). b Estimated time series of volumetric flows computed by inverse modeling (average values of the four best fitting models)

(a)

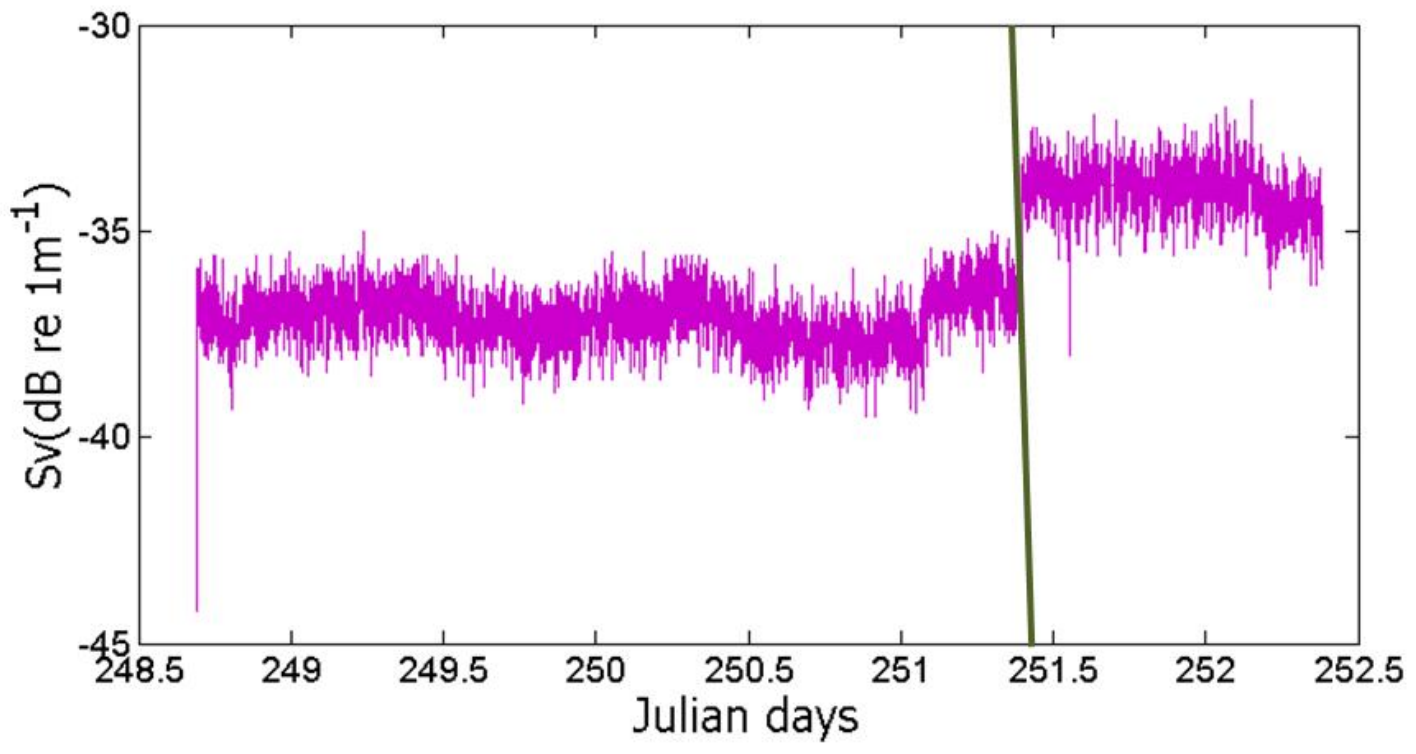

(b)

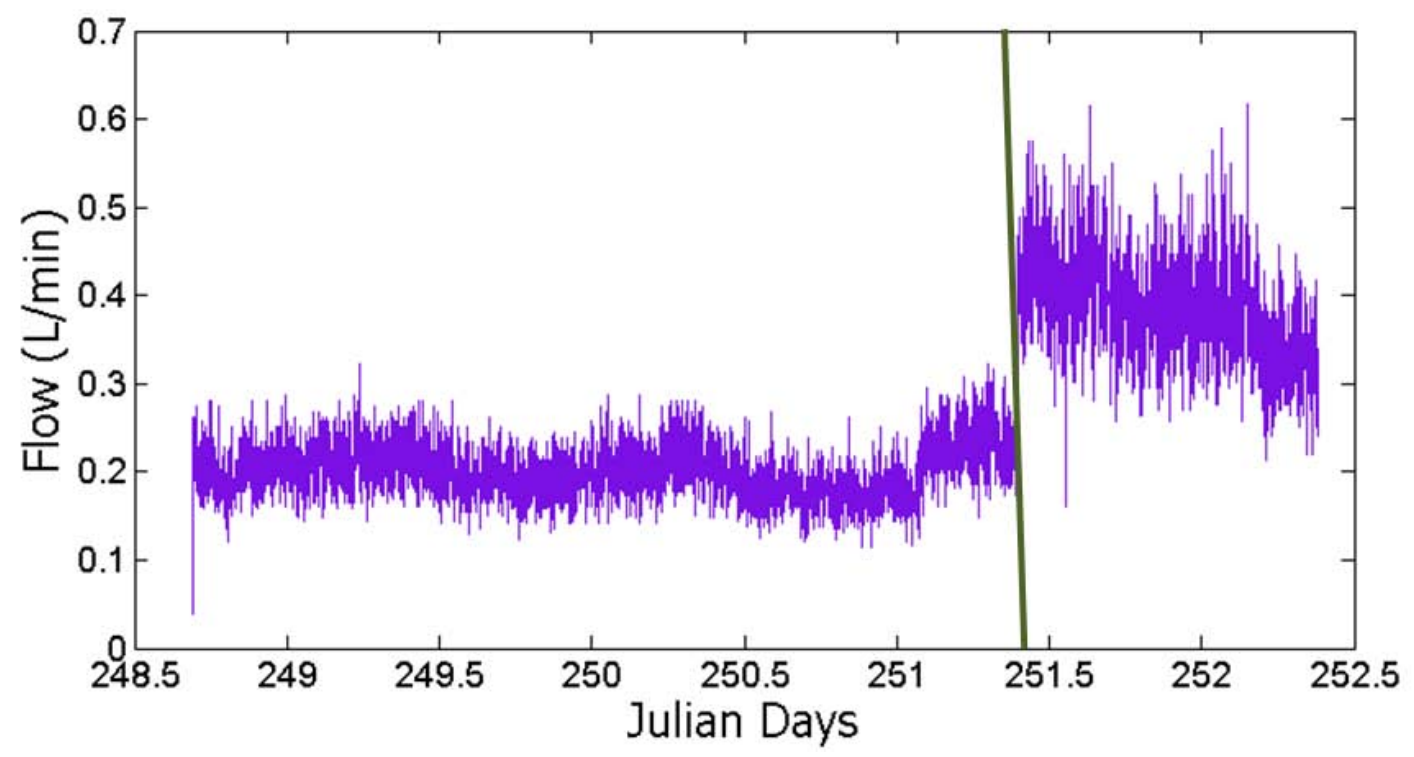


Fig. 8 Image plots of target strength values, TS, estimated with Stanton (a) and Medwin (b) equivalent sphere models, versus bubble depth and size distributions. Flatness coefficient $=$ 2. Color bar represents TS in decibels.

(a)

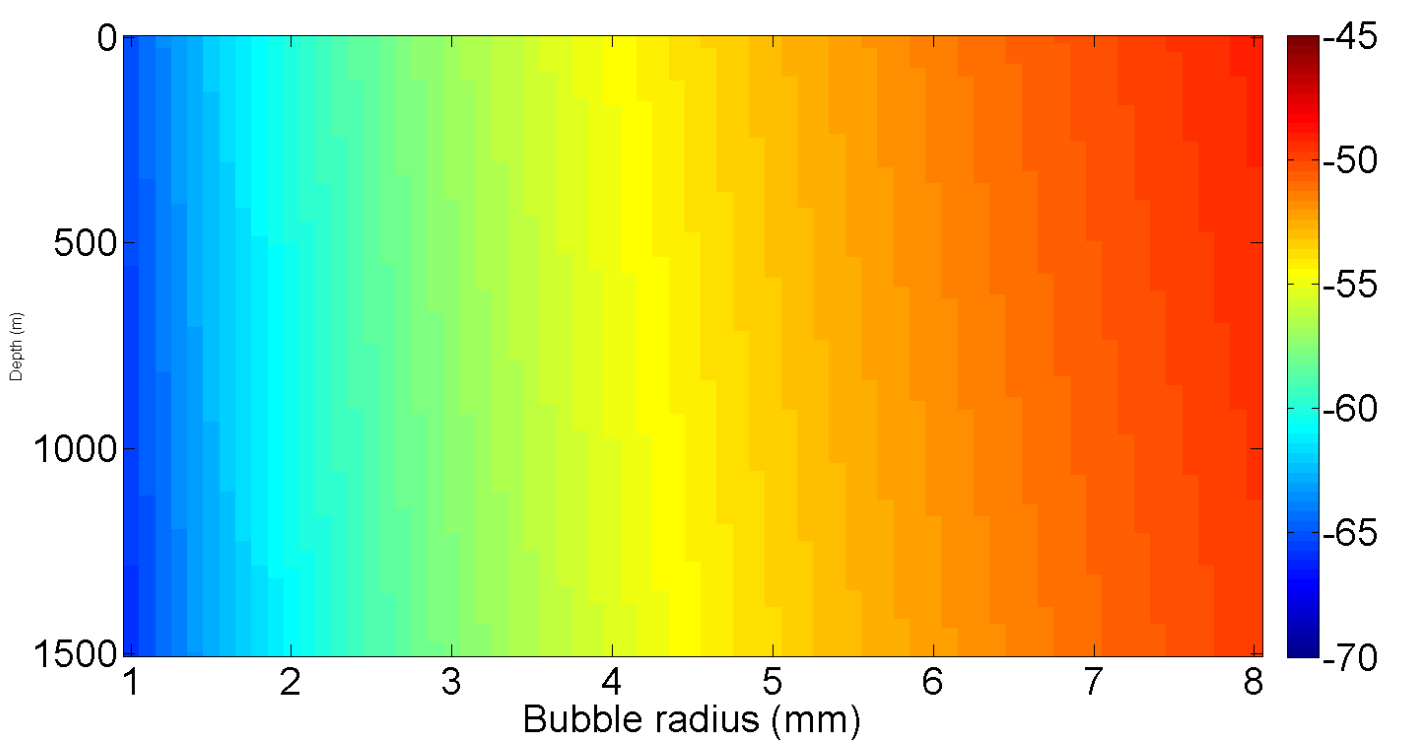

(b)

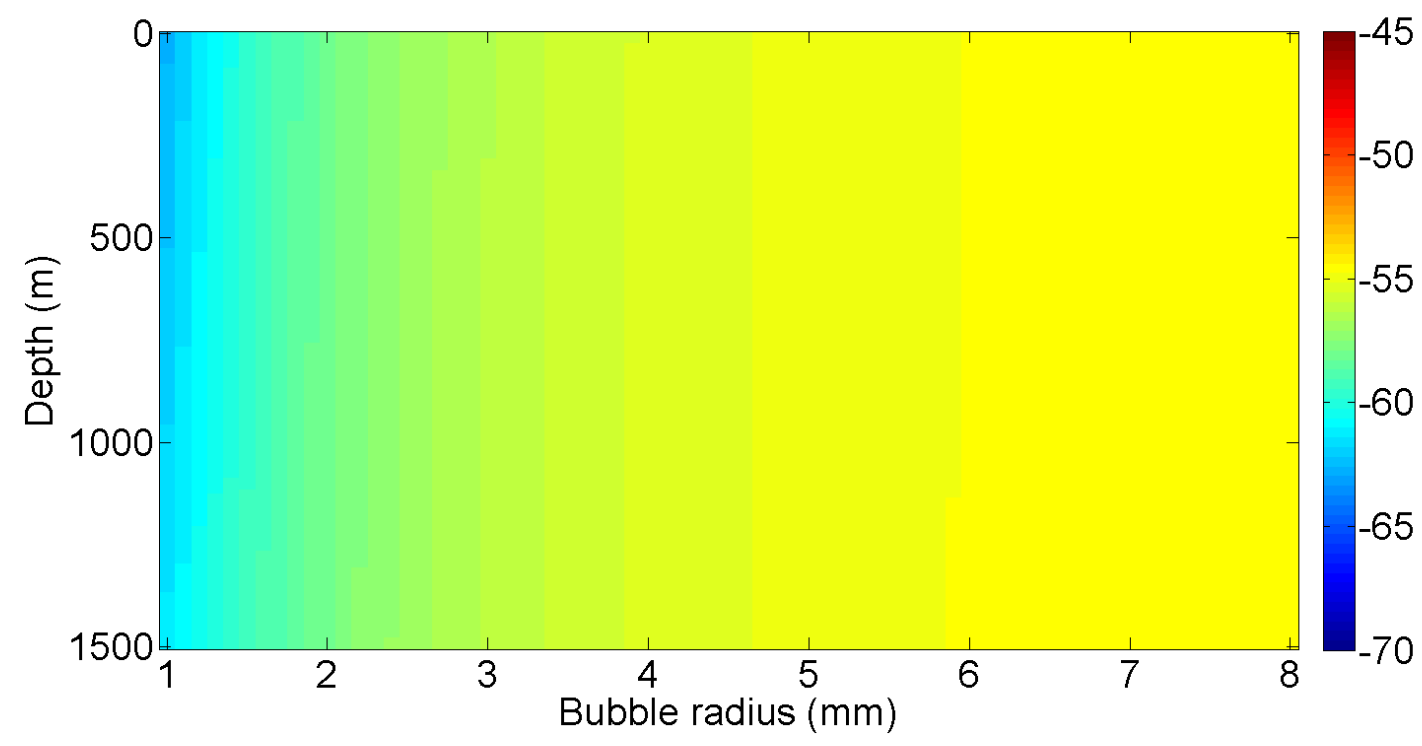


Fig. 9 a Image plot of the volume backscattering strength, $S_{v}$, estimated with the Stanton equivalent sphere model, for varying flow rates and transducer-to-bubble stream distances (color bar represents $S_{v}$ in $\mathrm{dB}$ re $1 \mathrm{~m}^{-1}$ ). b $S_{v}$ versus transducer-to-bubble stream distance for low flow rate $(0.01 \mathrm{l} / \mathrm{min})$, medium flow rate $(0.25 \mathrm{l} / \mathrm{min})$ and high flow rate $(0.5 \mathrm{l} / \mathrm{min})$ input values

(a)

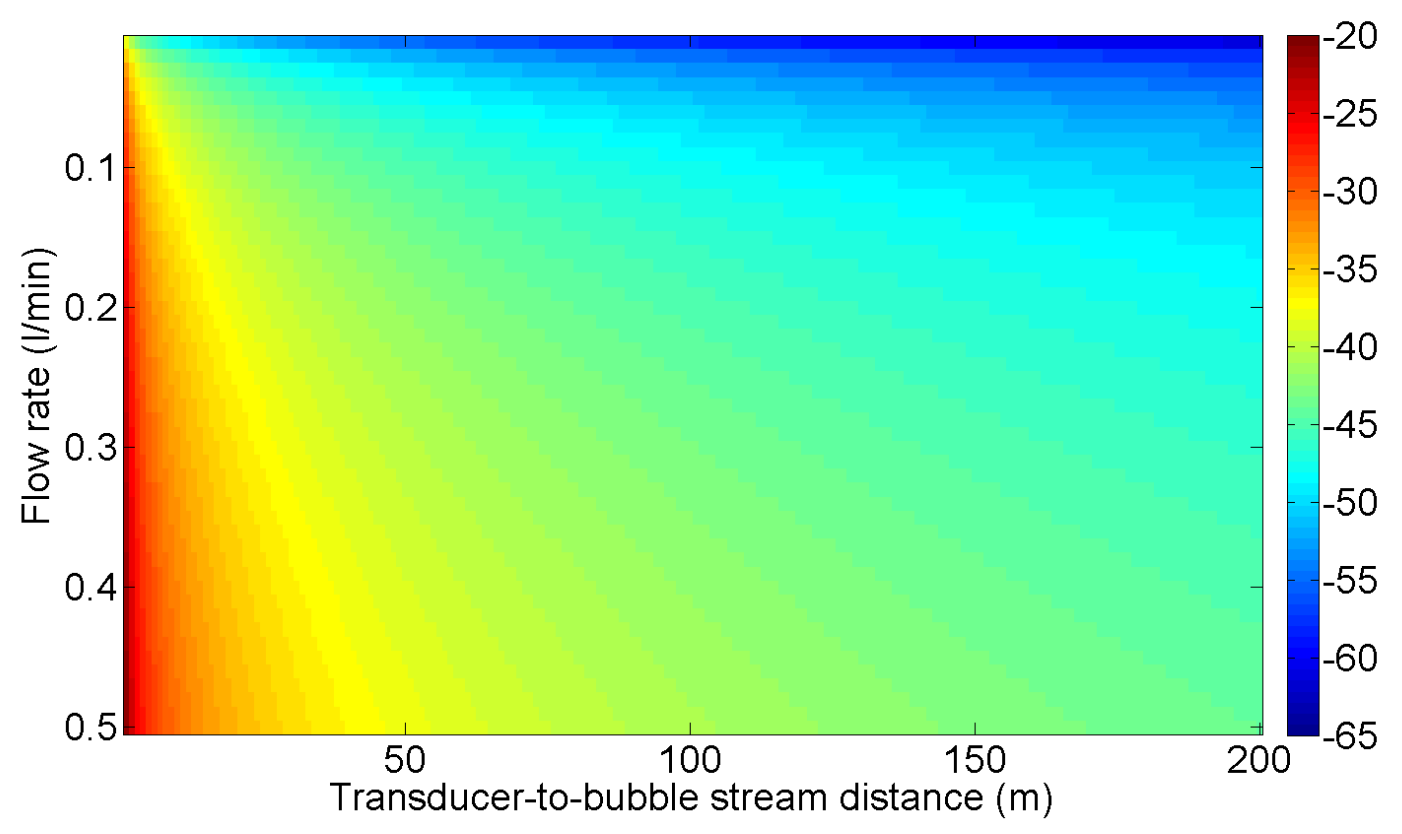

(b)

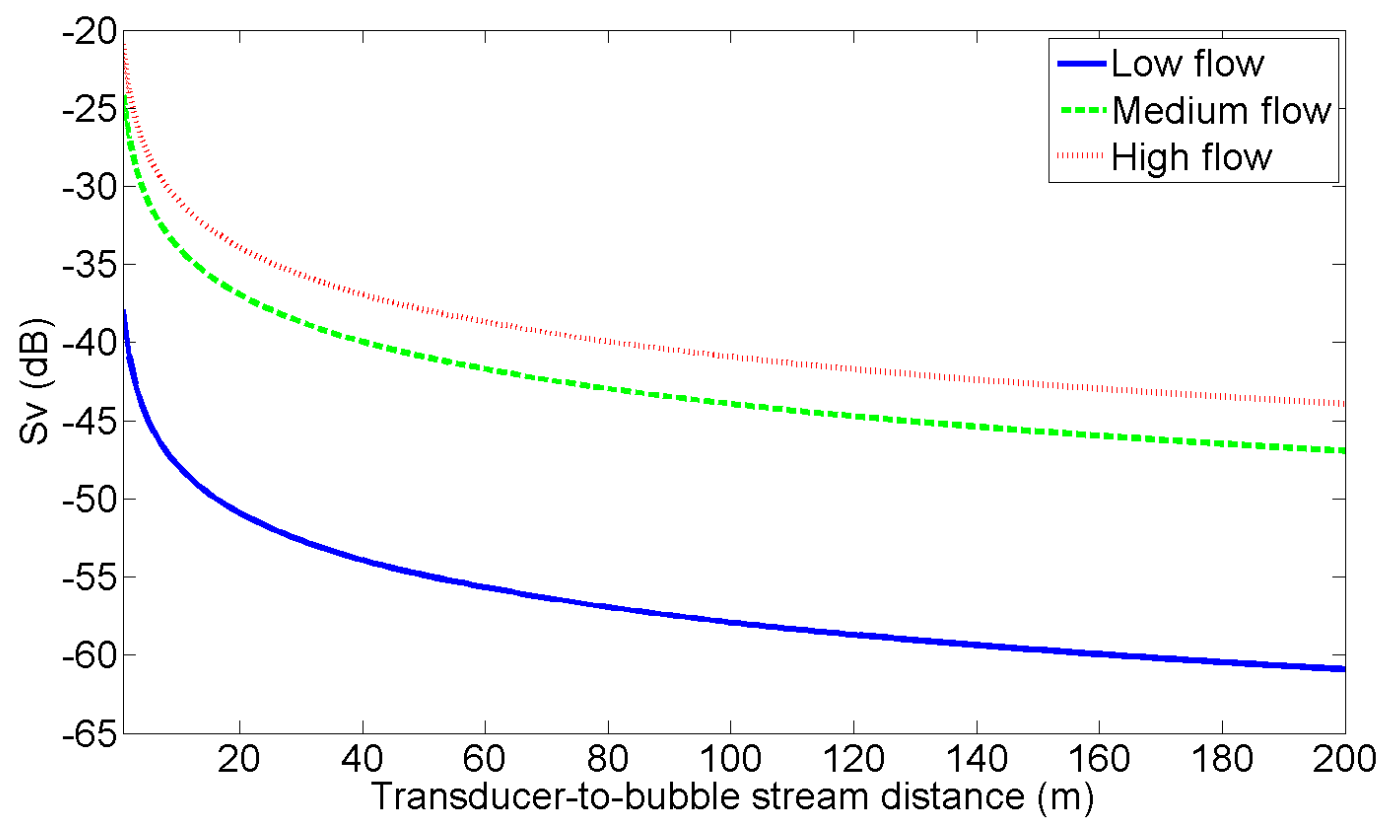


Fig. 10 a Image plot of the volume backscattering strength, $S_{v}$, estimated with the Stanton equivalent sphere model, for varying flow rates and bubble ascent rates (color bar represents $S_{v}$ in $\mathrm{dB}$ re $\left.1 \mathrm{~m}^{-1}\right)$. b $S_{v}$ versus bubble ascent rate for low flow rate $(0.01 \mathrm{l} / \mathrm{min})$, medium flow rate $(0.25 \mathrm{l} / \mathrm{min})$ and high flow rate $(0.5 \mathrm{l} / \mathrm{min})$ input values

(a)

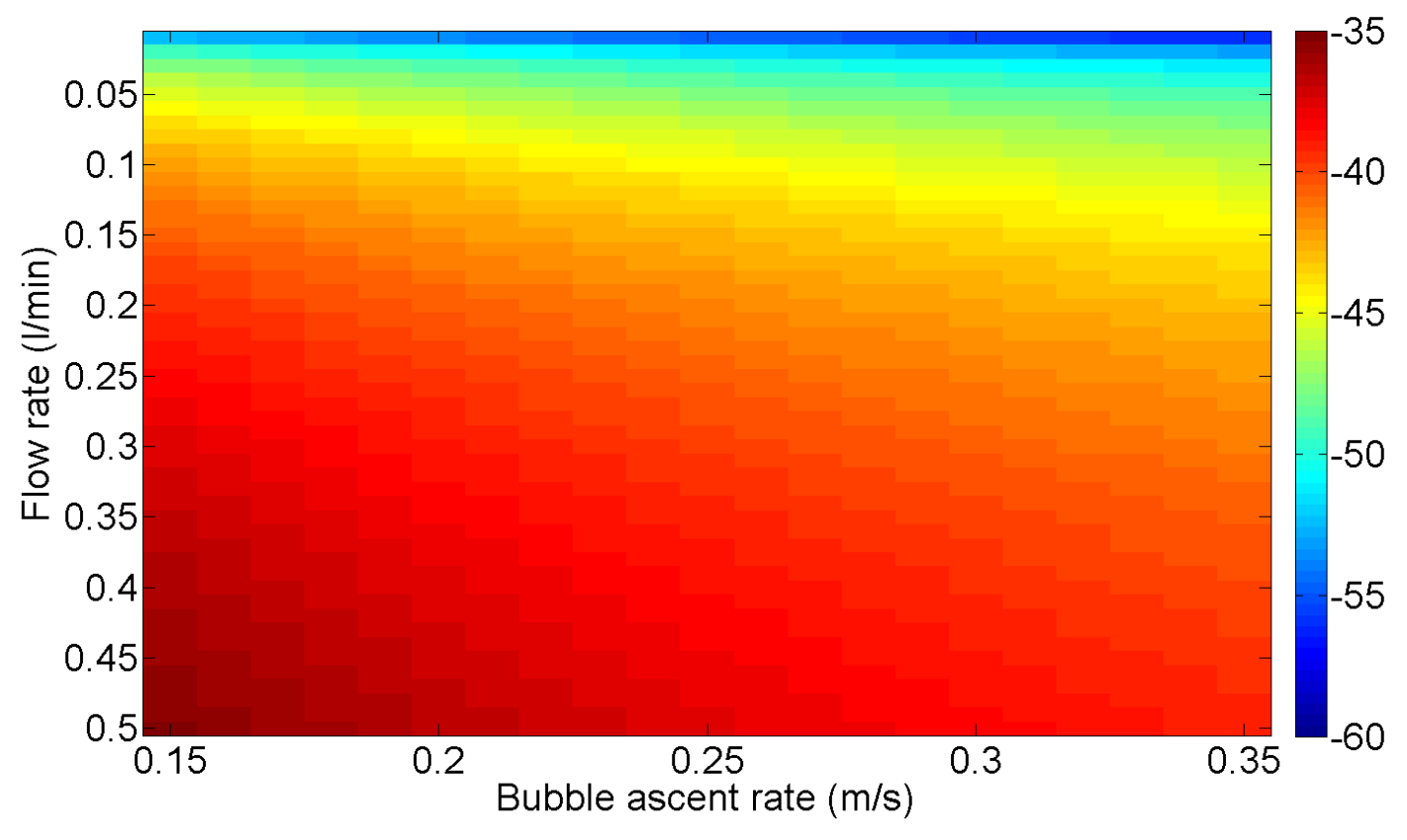

(b)

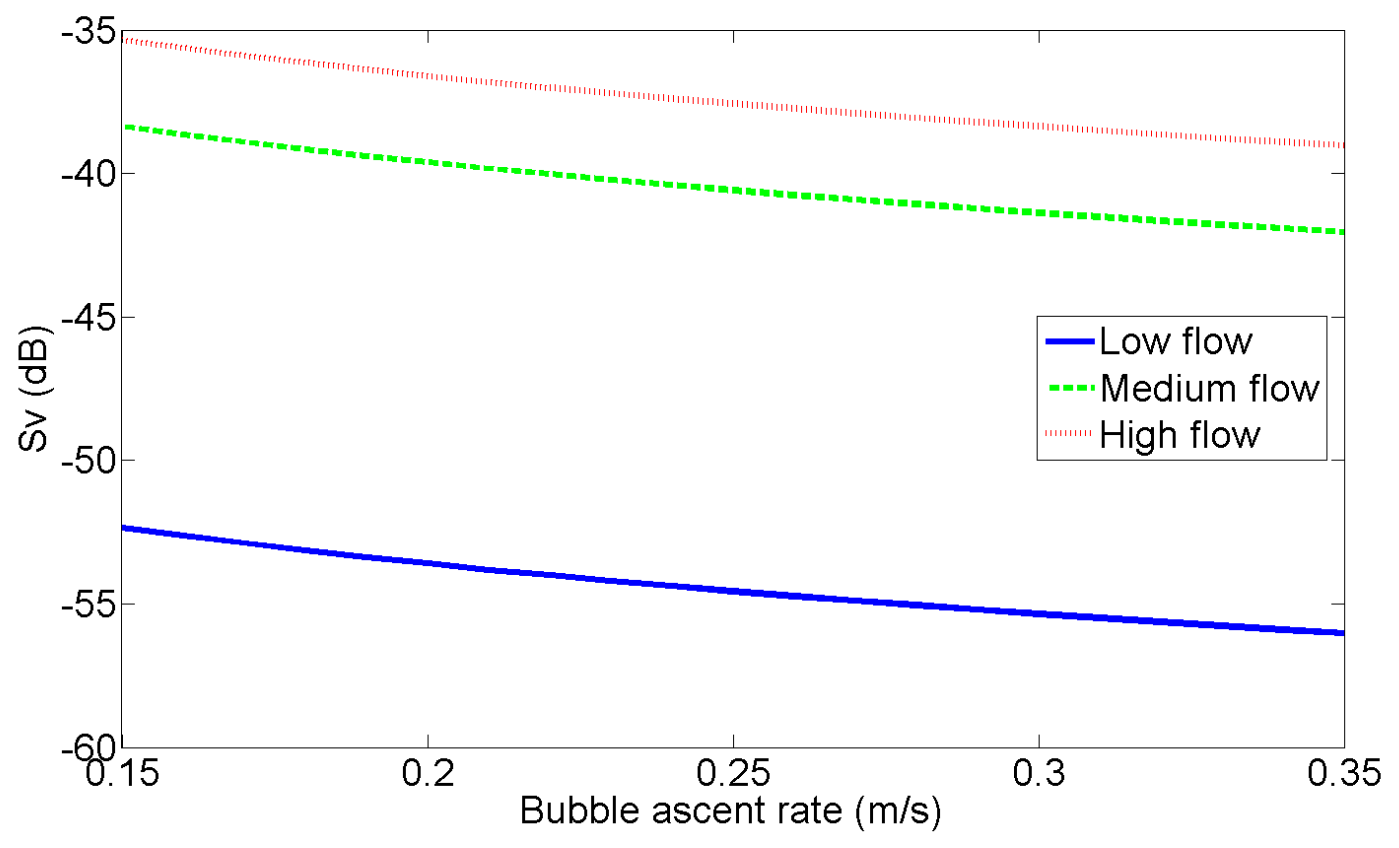


Fig. 11 a Image plot of the volume backscattering strength, $S_{v}$, estimated with the Stanton equivalent sphere model, for varying flow rates and bubble size distribution shifts (see text for explanation, color bar represents $S_{v}$ in $\mathrm{dB}$ re $\left.1 \mathrm{~m}^{-1}\right)$. b $S_{v}$ as a function of the bubble size distribution shift for low flow rate $(0.01 \mathrm{l} / \mathrm{min})$, medium flow rate $(0.25 \mathrm{l} / \mathrm{min})$ and high flow rate $(0.5 \mathrm{l} / \mathrm{min})$ input values

(a)

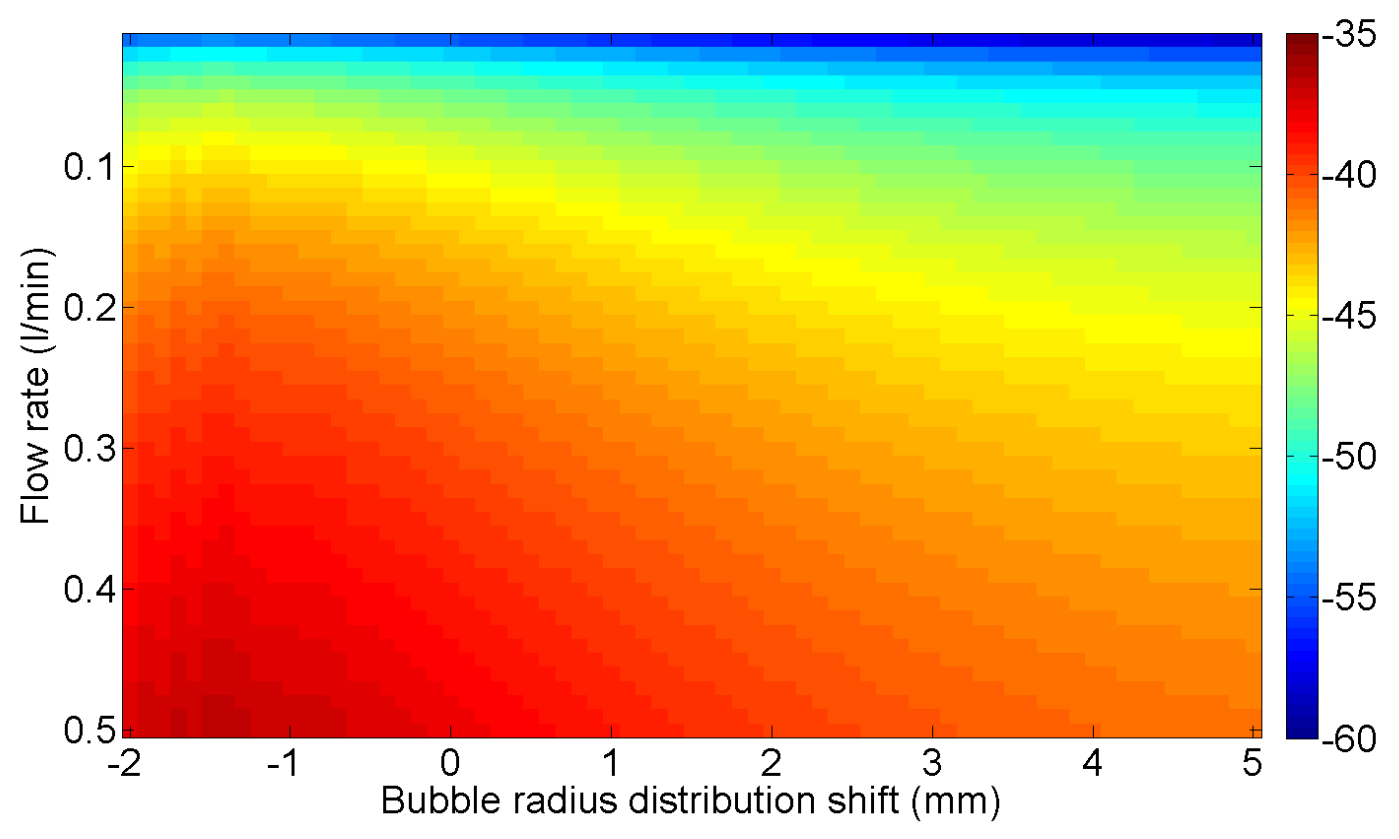

(b)

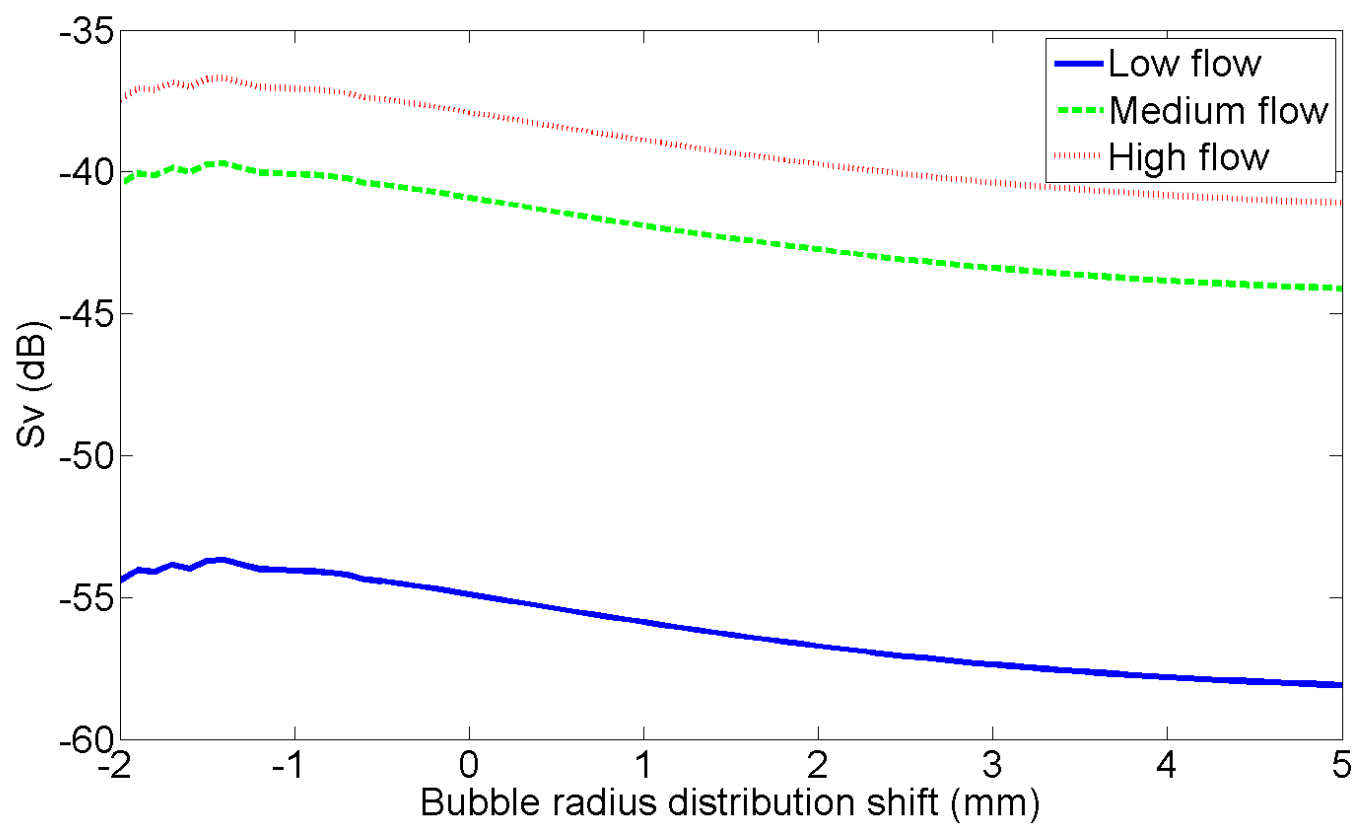


Fig. 12 a Volume backscattering attenuation coefficient versus beam across-angle position of a bubble stream for a $7^{\circ}$ circular beam pattern. b Bubble stream detection probability (color bar) for a $-60 \mathrm{~dB}$ volume backscattering strength threshold according to different flow rates and transducer-to-bubble stream distances (10 dB signal-to-noise ratio)

(a)

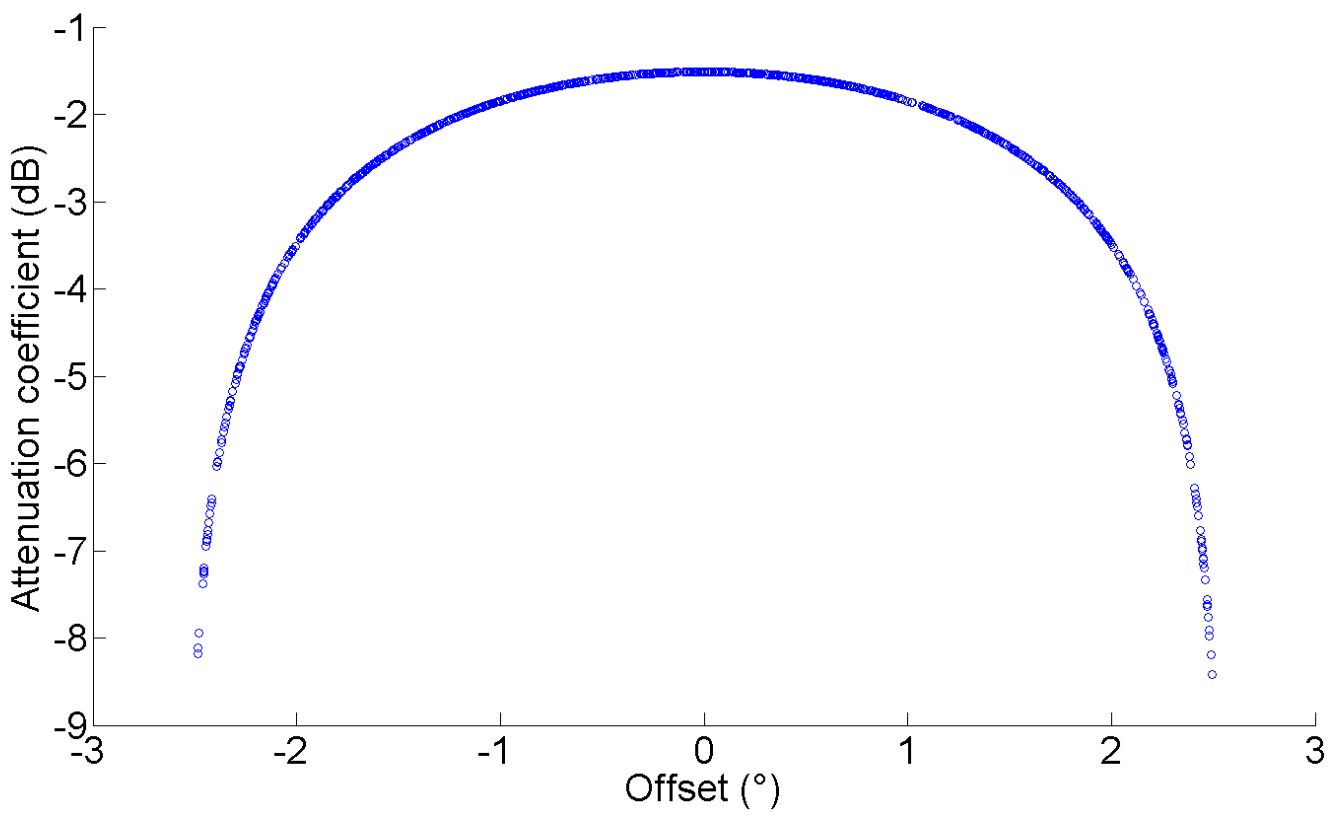

(b)

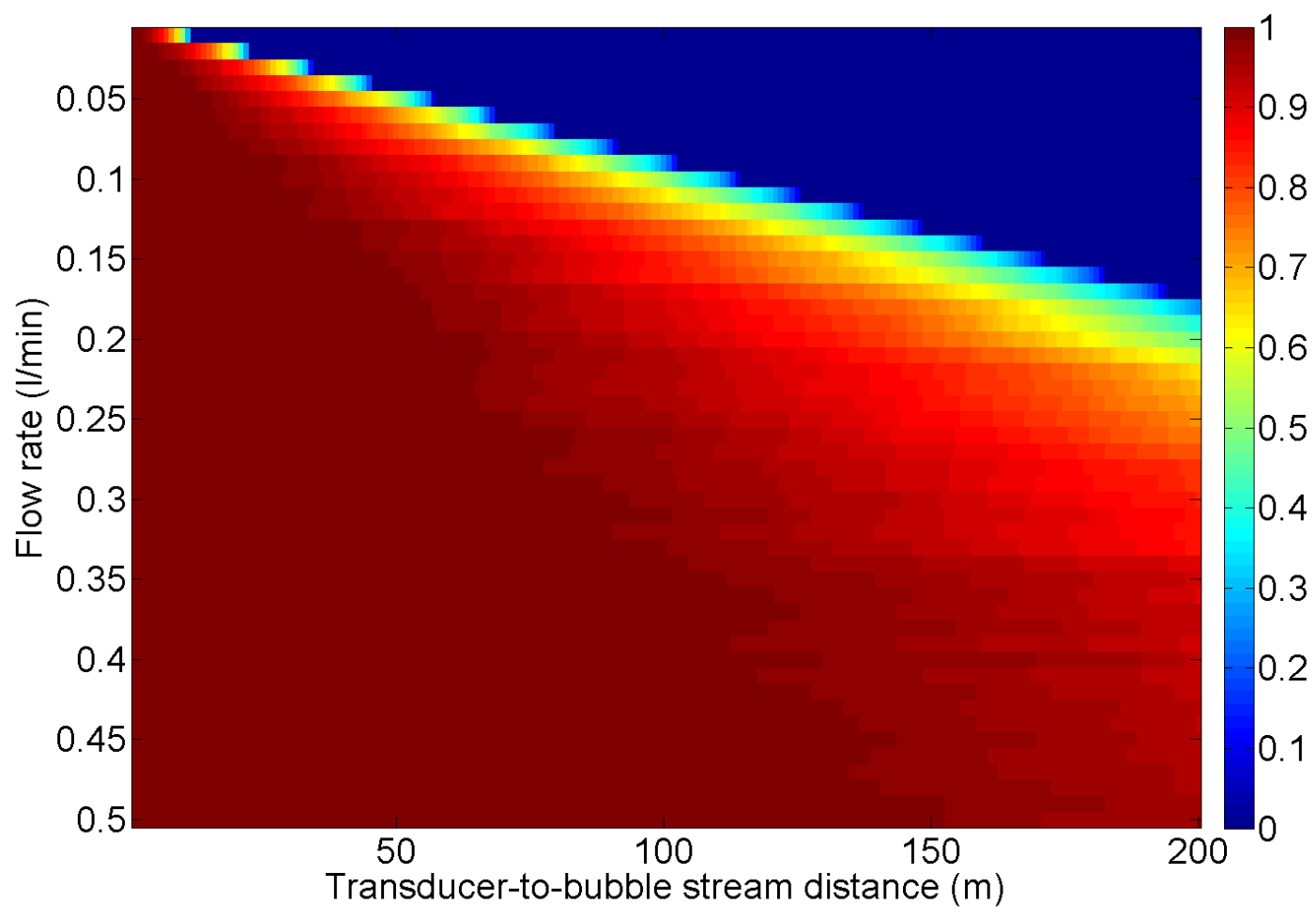

